\title{
A BIFURCATION ANALYSIS OF SPACE STRUCTURES BY USING 3D BEAM-COLUMN ELEMENT CONSIDERING FINITE DEFORMATIONS AND BOWING EFFECT
}

\author{
K.S. Lee ${ }^{1, *}$ and S.E. $\operatorname{Han}^{2}$ \\ ${ }^{1}$ Research Professor, Department of Civil \& Environmental Engineering \\ Korea Advanced Institute of Science and Technology, 373-1 Guseong-dong, Yuseong-gu, Daejeon, South Korea \\ ${ }^{2}$ Professor, Department of Architectural Engineering, School of Architecture \\ Inha University, 253 Yonghyundong, Nam-gu, Incheon, 402-751, South Korea \\ *(Corresponding author: E-mail: kslee77@kaist.ac.kr)
}

Received: 22 September 2011; Revised: 19 December 2011; Accepted: 30 December 2011

\begin{abstract}
The present paper describes the space frame element and the fundamental strategies in computational elastic bifurcation theory of geometrically nonlinear, single load parameter conservative elastic spatial structures. A method for large deformation (rotation) analysis of space frame is based on an Eulerian formulation, which takes into consideration the effects of large joint rotations with finite deformation(rotation). The local member force-deformation relationships are based on the beam-column approach, and the change in member chord lengths caused by axial strain and flexural bowing are taken into account. And the derived geometric stiffness matrix is asymmetric because of the fact that finite rotations are not commutative under addition. To detect the singular point such as bifurcation point, an iterative pin-pointing algorithm is proposed. And the path switching mode for bifurcation path is based on the non-negative eigen-value and its corresponding eigen-vector. Some numerical examples for bifurcation analysis for a plane frame, plane circular arch and space dome structures are described.
\end{abstract}

Keywords: Elastic stability, Bifurcation, Space frame, Eulerian, Finite deformation

\section{INTRODUCTION}

This paper deals with the theoretical aspects of bifurcation buckling of space frame for the elastic stability. An arc-length method is used for the nonlinear post-buckling numerical strategies and 3D beam-column equations are adopted to investigate the numerical characteristics of bifurcation buckling which is the most important critical state of elastic stability of space frame for the space frame element.

The pioneering research work of Koiter [1] and Thompson and Hunt [2] focused on the general theory of elastic stability. Their studies were understood as the milestone work on the formulation of the basic theory of elastic stability theory and play an important role in establishing the theory of elastic stability problems, but there is a limitation to apply the higher order mathematical stability theories to the analytical methods such as finite element method.

Therefore, in recent years, it is applied to the actual problems of elastic stability by co-operating the arc length method [3-11] and the theory of nonlinear finite element method. Recently analytical theory of elastic stability including bifurcation analysis was introduced in references [9-11]. From the theory of elastic stability, buckling of elastic structure can be divided into snap-through, snap-back and bifurcation buckling, and commonly, bifurcation called as buckling of structures. The critical stability points in nonlinear elasticity may be classified into limit and bifurcation point. The snap through and snap back buckling has the characteristics of the limit point, and bifurcation has the characteristics of bifurcation point. 
For limit point buckling, the path tracing scheme to successively compute the regular equilibrium points on the equilibrium path and the pinpointing scheme to precisely locate the singular equilibrium points are sufficient for the computational stability analysis. For bifurcation points, however, a specific procedure for path-switching is also necessary to detect the branching paths to be traced in the post buckling region. Generally, limit point buckling often occurred when the concentrated load is imposed at the apex of dome shaped shallow shell structure. And bifurcation buckling often occurred when the uniform loads of space structures subjected to compressive forces.

The indirect [3-5, 9-14] and direct methods [11,15-21] are proposed to detect the bifurcation point respectively. The detection of bifurcation point is determined by the detection parameter while equilibrium path is being traced with indirect method. With direct method, the extended system, which is a new set of equations added to the original set of nonlinear equilibrium equations, is solved to obtain both the critical point and its associated eigen-mode.

To search the complex equilibrium path of primary and bifurcation path of post buckling range, the space frame element should consider a finite rotation due to the geometric large deformation and elastic element force. Both a beam-column approach [22-26], based on the member basic force and deformation relationships, and a finite element approach [27-41] has been used in developing the nonlinear governing equations. The large-deformation geometrically nonlinear analysis is carried out by various methods of treatment of the non-vectorial nature of rotations, the selection of coordinate systems of the stress-strain tensor and the linearization of variational equations. Large rotations are usually represented by Euler's finite theory [27, 32] and applied to both beam-column [23-26] and finite element theory [27-33]. Agyris et al. [27-31] introduced so-called semi-tangential rotations to circumvent the non-vectorial or non-commutative behavior of successive finite rotations about fixed axes. An alternative way of deriving efficient non-linear finite element models is the co-rotational approach [34-40]. The main idea of this approach is to decompose the motion of the element into rigid body and pure deformational parts through the use of a reference system that continuously rotates and translates with the element. The procedure for the co-rotational approach is similar to the Eulerian finite rotation of a beam-column element. Most of these finite element nonlinear analysis techniques are based on assumed displacement fields and require a large number of elements to model a structure with large deformation. However it is known that an Eulerian formulated beam-column approach with bowing effect $[24,25]$ can produce a sufficient solution with one element per member different from finite element formulations.

In this study, to identify the characteristics of critical point, which separated into the limit and bifurcation point, the indirect method was used to search the critical points through the calculation of parametric variable determined by the smallest eigen-value without considering the higher order terms in equilibrium equation. And unlike previous studies, which had used the smallest eigen-value only for the case of single bifurcation, in this study, the smallest eigen-value and corresponding eigen-vector are used to switch to the bifurcation path for single and multiple bifurcation analysis. And to perform the highly nonlinear post buckling analysis such as bifurcation, a space frame element that reflects the large deformation, rigid body motion and relative deformation are calculated according to the theory of Spiller [23] and Levy and Spiller [26] for Eulerian finite rotation of a 3D space frame. The elastic beam-column formulations of Kassimali and Abbasnia [24] are also adopted. The effects of axial force on the member bending moment (bowing effect) are included in the analysis. The asymmetric tangent stiffness matrix due to the finite rotation of space frame element, derived by Spiller [23] and Levy and Spiller [26], is used to include some symmetric and asymmetric buckling modes in physical situations. However, the effect of axial force on the member's torsional stiffness (Wagner effect) and warping effect are omitted for simplicity. 
Finally, numerical examples for elastic bifurcation analyses were carried out for the proposed simple and efficient bifurcation algorithm with large deformation space frame element to demonstrate accuracy and efficiency.

\section{THEORY OF ELASTIC STABILITY}

The potential energy of structures can be written as follows

$\boldsymbol{\Pi}(\mathbf{d}, \lambda)=\mathbf{U}+\mathbf{V}$

$\boldsymbol{\Pi}$ : total potential energy, $\mathbf{U}:$ strain energy, $V$ : external work,

$\mathbf{d}$ : displacement, $\lambda$ : scalar load parameter

The variation of potential energy $\delta \Pi$ can be expressed from the Taylor expansion of Eq. 1 as follows

$$
\delta \boldsymbol{\Pi}(d, \lambda)=\frac{\partial \boldsymbol{\Pi}}{\partial \mathbf{d}} \delta \mathbf{d}+\frac{1}{2} \delta \mathbf{d}^{T} \frac{\partial^{2} \boldsymbol{\Pi}}{\partial \mathbf{d}^{2}} \delta \mathbf{d}+\mathbf{O}\left(\delta \mathbf{d}^{3}\right)
$$

From Eq. 2, by applying the well known equations for potential energy, a residual vector, $\mathbf{g}(\mathbf{d}, \lambda)=\partial \boldsymbol{\Pi} / \partial \mathbf{d}$ and a tangent stiffness matrix, $\mathbf{K}_{t}=\partial^{2} \boldsymbol{\Pi} / \partial \mathbf{d}^{2}$, and omitting the higher order term, the Eq. 2 can be rewritten as follows

$$
\delta \boldsymbol{\Pi}(\mathbf{d}, \lambda)=\mathbf{g}^{T} \delta \mathbf{d}+\frac{1}{2} \delta \mathbf{d}^{T} \mathbf{K}_{t} \delta \mathbf{d}
$$

From the stationary condition of potential energy in equilibrium state, the equation of structure in equilibrium state can be represented as follows.

$$
\boldsymbol{\Pi}_{, \delta \mathbf{d}}=\mathbf{g}(\mathbf{d}, \lambda)=\mathbf{F}(\mathbf{d})-\lambda \mathbf{P}=0
$$

In addition, the second term in Eq. 2 should be positive value according to the theory of stability in conservative system, and this condition can be expressed as follows in matrix form.

$$
\Pi_{, \delta \mathbf{d}^{2}}=\frac{1}{2} \delta \mathbf{d}^{T} \mathbf{K}_{t} \delta \mathbf{d}>0
$$

It called as unstable state, if above equation is not positive value.

The state changes of stability point on equilibrium path, [d, $\lambda]$ represent the change of value Eq. 5 $\Pi, \delta \mathbf{d}^{2}$ from positive to negative.

And these state changes on equilibrium path called as critical state or critical point. In this paper, parameters $l$ and $*$ for the length of equilibrium path, represent the critical point, satisfying the following relationship.

$$
\left(\mathbf{d}^{*}, \lambda^{*}\right)=\left(\mathbf{d}\left(l^{*}\right), \lambda\left(l^{*}\right)\right)
$$

$\mathbf{K}_{t}\left(\mathbf{d}^{*}, \lambda^{*}\right) \mathbf{x}=0$ 
The definite definition for critical point of Eq. 7 can be obtained which satisfy the condition of $\omega_{j}=0$ in generalized eigen-value problem as follows.

$\left|\mathbf{K}_{t}-\omega_{j} \mathbf{I}\right| \boldsymbol{\varphi}_{j}=0$

Where $\omega_{j}$ is $\mathrm{j}$-th eigen-value in Eq. 8. Another expression for critical point in stability condition is represented by a determinant of tangent stiffness matrix which satisfying the necessary condition only as follows.

$D=\operatorname{det}\left|\mathbf{K}_{t}\right|=0$

We can obtain the expression for stable condition in equilibrium state, by using the value for eigen-value $\omega_{j}$. The system may remain in the stable state until the eigen-value $\omega_{j}$ of N-DOF satisfy the following equation.

$0<\omega_{1} \leq \omega_{2} \leq \omega_{3} \cdots \cdots \leq \omega_{N}$

It reaches the critical or stability limit state when $\omega_{j}$ may have the following values.

$0=\omega_{1}=\omega_{2} \cdots=\omega_{k}<\omega_{k+1} \cdots \cdots \leq \omega_{N}$

The single critical condition, $k=1$ means that the minimum eigen-value satisfies zero value $\omega_{k}=0$ only. Where multiple critical condition, $k>1$ means multiple numbers of eigen-value are zero value simultaneously. In this study, we considered the single and multiple critical states for stability point.

The new equation for residual vector of Eq. 4 can be obtained from the Taylor series expansion about equilibrium state, $\left[\mathbf{d}_{0}, \lambda_{0}\right]$ as follows.

$\mathbf{g}(\mathbf{d}, \lambda)=\mathbf{g}\left(\mathbf{d}_{0}, \lambda_{0}\right)+\frac{\partial \mathbf{g}}{\partial \mathbf{d}_{0}} \Delta \mathbf{d}+\frac{\partial \mathbf{g}}{\partial \lambda_{0}} \Delta \lambda+O\left(\Delta \mathbf{d}^{2}, \Delta \lambda^{2}, \Delta \mathbf{d} \Delta \lambda\right)$

If we assume the initial equilibrium state, $\mathbf{g}(\mathbf{d}, \lambda)=\mathbf{g}\left(\mathbf{d}_{0}, \lambda_{0}\right)=0$ and omitting the higher order term in Eq. 12, The new expression for Eq. 12 can be obtained as follows.

$\frac{\partial \mathbf{g}}{\partial \mathbf{d}_{0}} \Delta \mathbf{d}+\frac{\partial \mathbf{g}}{\partial \lambda_{0}} \Delta \lambda=\mathbf{K}_{t} \Delta \mathbf{d}-\Delta \lambda \mathbf{P}=0$

The critical point which represents the condition of change of state, stable to unstable or unstable to stable, the minimum eigen-value may be zero value, $\omega_{1}=0$ on equilibrium path. And applying the corresponding minimum eigen-vector, $\boldsymbol{\varphi}_{1}$ to Eq. 13, the new expression for Eq. 13 can be obtained as follows.

$\Delta \mathbf{d}^{T} \mathbf{K}_{t} \boldsymbol{\varphi}_{1}-\Delta \lambda \mathbf{P}^{T} \boldsymbol{\varphi}_{1}=0$

The left first tem of Eq. 14 can be omitted from the relationship of Eq. 7. Therefore, Eq. 14 can be rewritten as follows. 


$$
\Delta \lambda \mathbf{P}^{T} \boldsymbol{\varphi}_{1}=0
$$

The satisfactory condition of Eq. 15 can be classified as following two cases.

$$
\begin{array}{ll}
\mathbf{P}^{T} \boldsymbol{\varphi}_{1} \neq 0, \Delta \lambda=0 & : \text { Limit point } \\
\mathbf{P}^{T} \boldsymbol{\varphi}_{1}=0, \Delta \lambda \neq 0 & : \text { Bifurcation point }
\end{array}
$$

As a result, Eqs. 16 and 17 represent the condition of separating the critical point by limit and bifurcation point. Therefore, we can divide the critical point of system by using the Eq. 16. If the bifurcation point is detected by using these equations, the post buckling equilibrium path is switched to the bifurcation of branching path in primary path by using following path switching algorithm.

\section{SEARCH FOR EQUILIBRIUM PATH}

The arc-length method can be considered as the most efficient numerical method to calculate the nonlinear equilibrium path. The general displacement or load incremental method using the Newton-Raphson method cannot exactly calculate the equilibrium path beyond an inflection point, such as limit point because of using only one parameter to control the analysis process. However the arc-length method can calculate the displacement and load parameter $[\mathbf{d}, \lambda]$ simultaneously, by using the arc-length constraint which is a function of pre-defined arc-length parameter, $\Delta l$.

When using the arc-length method, the incremental displacement and load parameter $[\Delta \mathbf{d}, \Delta \lambda] \operatorname{can}$ be calculated by using the following simultaneous equations in predictor process.

$$
\mathbf{K}_{t} \Delta \mathbf{d}-\Delta \lambda \mathbf{P}=0
$$

$\Delta \mathbf{d}^{T} \Delta \mathbf{d}-b \Delta \lambda^{2} \mathbf{P}^{T} \mathbf{P}=\Delta l^{2}$

$b$ : proportional constant, $\Delta l:$ arc-length parameter

The arc-length method can be classified into a spherical and cylindrical arc-length method according to the value of proportional constant, $b$ in Eq. 18. In this paper, the spherical arc-length method [3-5] is employed by using $b=1$.

The Iterative displacement and load parameter $[\delta \mathbf{d}, \delta \lambda]$ can be calculated by using following simultaneous equations which are linearized form of Eqs. 17 and 18, in corrector process.

$$
\begin{gathered}
\mathbf{K}_{t} \delta \mathbf{d}-\delta \lambda \mathbf{P}=\mathbf{g}\left(\mathbf{d}_{i}, \lambda_{i}\right) \\
\Delta \mathbf{d}^{T} \delta \mathbf{d}-b \Delta \lambda \delta \lambda \mathbf{P}^{T} \mathbf{P}=0
\end{gathered}
$$

From the iterative corrector process, the converged equilibrium point on primary path can be solved by using the pre-defined arc-length parameter, $\Delta l$ in predictor process. The incremental displacement and load parameter are updated by using the following equations.

$$
\lambda_{i+1}=\lambda_{0}+\Delta \lambda_{i+1}=\lambda_{0}+\delta \lambda_{i+1}
$$


$\mathbf{d}_{i+1}=\mathbf{d}_{0}+\Delta \mathbf{d}_{i+1}=\mathbf{d}_{i}+\eta_{i} \delta \mathbf{d}_{i}$

$\Delta \mathbf{d}_{i+1}=\Delta \mathbf{d}_{i}+\eta_{i} \delta \mathbf{d}_{i}$

$\eta_{i}=\rho \Delta l_{i}$

In Eq. 23 and 24, $\eta_{i}$ is proportional parameter to the tangent of equilibrium path, and $\rho$ is proportional constant to the arc-length $\Delta l$ which have the value $0<\rho \leq 1$.

\section{DETECTION FOR CRITICAL POINT}

In general, the buckling load may be determined by the value of eigen-value or determinant of tangent stiffness matrix in nonlinear buckling analysis process. The method described above is indirect method [3-5,9-14] for buckling analysis which is determined by a specific detecting parameter such as minimum eigen-value or arc-length $\Delta l$. However, opposed to the indirect method, direct method [11,15-21] uses the extended system to solve both the position of critical point and its associated eigen-mode directly. The extended system represents the condition for the occurrence of critical point.

In this paper, simple and efficient indirect method is used to solve the critical point. A value of arc-length $\Delta l$ is used for the deterministic parameter of indirect method, whether critical point may be reached or not. The eigen-value of Eq. 8 is used to calculate the detecting parameter, arc-length $\Delta l$. If $\Delta l$ is zero or nearly zero, $\Delta l \cong 0$, we determined that the system is unstable critical point. Whether the critical point is the limit or bifurcation point is determined by the conditional equation of Eqs. 16-a, 16-b.

The method of using the value of determinant is applicable to detect the critical point and state of primary path $[10,13,14,19,20]$. However it is not proper to use the determinant to calculate the arc-length parameter $\Delta l$. The reason is that the numerical error may occur to calculate the determinant of unstable tangent stiffness matrix. Therefore null value of the arc-length may be obtained, when the arc-length is close to zero value. The method of using the eigen-value enables us to calculate more accurate critical point and arc-length than to use the determinant, despite more calculations are needed.

The condition of structures can be determined by the value of eigen-vaule of tangent stiffness matrix. When a structure is unstable status of critical point such as bifurcation or limit point, the calculated eigen-value is shown as a null or negative value.

In equilibrium primary path, incremental length of primary path and structural stability has proportional relationship. When the structure is linear and stable, the large value of incremental length of primary path is possible. In other words, the corresponding large value of arc-length can be possible in this situation. And non-zero, relative large value of eigen-value would is obtained by using current tangent stiffness matrix. In contrast, near the critical point such as bifurcation or limit point, we should reduce the incremental length of primary path for the convergence by using smaller value of arc-length. And the condition of tangent stiffness matrix, eigen-value or determinant approaches to almost ill or negative at this point. In general, the more accurate eigen-value is appropriate than determinant. 
The arc-length can be predefined as a fixed constant value, however this case is only valid for general nonlinear analysis or snap-through/snap-back buckling analysis. In bifurcation analysis, the pinpointing algorithm should be performed to detect the bifurcation point. Since the length of equilibrium path should be influenced by the value of eigen-value. And this can be done by relating the arc-length to the eigen-value efficiently. After that, the arc-length can be variable parameter for detecting and convergence according to the eigen-value. The predefined value arc-length is only required for initial reference value. Therefore the incremental length of primary path can be controlled by the arc-length.

Since, it is clear that the arc-length and eigen-value related dependently. When the arc-length is related to the eigen-value, the more accurate stability analysis is possible to detect the critical point. The arc-length control method with variable and parametric value is appropriate for the stability analysis. It can trace the complex shape of primary and bifurcated path.

Let the arc-length $l_{k}$ up to the k-step of equilibrium path, and then the following equation can be derived from the Taylor expansion of the eigen-value $\omega\left(l^{*}\right)$ at critical point $l^{*}$.

$$
\omega\left(l^{*}\right)=\omega\left(l_{k}\right)+\dot{\omega}\left(l_{k}\right) \Delta l_{k}+\frac{1}{2} \ddot{\omega}\left(l_{k}\right) \Delta l_{k}^{2}+\cdots
$$

The smallest non-negative eigen-value should be zero or nearly zero $\omega_{1}\left(l^{*}\right) \cong 0$ at certain critical point.

In this study, by re-odering the eigen-value [10] for each eigen-value, non-negative the zero or nearly zero-valued eigen-value is set to be the smallest eigen-value. And the corresponding eigen-vector is used to carry out the path switching to the bifurcation path.

The equation of arc-length at k-step, $\Delta l_{k}$ can be described with the omitting of higher order term in Eq. 25 as following.

$$
\Delta l_{k}=-\frac{\omega_{1}\left(l_{k}\right)}{\dot{\omega}_{1}\left(l_{k}\right)} \cong-\frac{\omega_{1}\left(l_{k}\right) \Delta l_{k-1}}{\omega_{1}\left(l_{k}\right)-\omega_{1}\left(l_{k-1}\right)}
$$

As it approaches the critical point, the arc-length is also close to zero, $\Delta l_{k} \rightarrow 0$. Therefore the following equation is used to determine the critical point.

$$
\Delta l_{k}<\varepsilon \Delta l_{1}
$$

$\varepsilon$ : criterion for convergence(0.01)

Unlike previous studies of single bifurcation problems [3-5,11], Eq. 25 to Eq. 27 have been applied to the single and multiple bifurcation problems simultaneously in this study. The detection of bifurcation is performed by the value of arc-length of Eq. 27. The corresponding eigen-vector is used for the path switching algorithm in the following section. 


\section{PATH SWITCHING ALGORITHM}

When the exact solution vector arrives near the bifurcation point on primary path, the initial approximate solution can be represented as the following equation by summing the approximate bifurcation mode $\tilde{\mathbf{d}}_{i}$ to the exact solution of bifurcation point $\mathbf{d}_{i-1}$.

$\mathbf{d}_{i}=\mathbf{d}_{i-1}+\eta_{i} \tilde{\mathbf{d}}_{i}$

In above equation, $\eta_{i}$ is the assumed constant for the bifurcation mode $\tilde{\mathbf{d}}_{i}$ at $\mathrm{i}$-th step. Unit value is applied to the value of $\eta_{i}$ in this study. Crisfield [10] and Wriggers et al. [15] considered the higher order term to calculate the approximate bifurcation mode. However in this study, the smallest eigen vector [3-5,12-14,18] which corresponds to the re-ordered smallest eigen-value in previous section, is used for the bifurcation mode of Eq. 28 to both cases of single and multiple bifurcation problems. Additional variable is not required. Recently Fujii and Noguchi [20] studied the bifurcation problems without using the eigen vector.

After path switching to secondary bifurcation path, the structure may undergo new deformation mode comparable to perfect system of primary path. The identical numerical methods are used to trace the bifurcation path. There is no difference and also for the critical point in that path. The detection and path switching to another path may occur. The processes of path tracing and switching to secondary bifurcation path are illustrated in verification examples in following section.

In the bifurcation problems for space frame element, to detect and to switch to the bifurcation path, accurate eigen-value and corresponding eigen vector of tangent stiffness matrix are the most important factor. The simple but efficient algorithm of this study of bifurcation buckling analysis is sufficient to obtain the accurate solution of verification examples. The more important factor is the accurate element formulation. In this study, the exact element theory of large deformational Eulerian formulation of space frame element with bowing effect and asymmetric tangent stiffness which reflect the moment coupling effect is used to calculate the eigen-value and corresponding eigen-vector. The formulations of space frame element based on the beam-column equation are described in the following section.

\section{ELASTIC SPACE FRAME ELEMENT}

For the successful analysis of elastic stability problem, especially bifurcation, the accurate tangent stiffness matrix of structure is essential for corresponding eigen-value and eigen-vector. In this section, to this end, general theoretical formulations and computational algorithms have been developed for planer and space frames. One should include the formulation of a large deformational effect to analyze the post-buckling and bifurcation analysis of the space frame. Since, in this study, a method for large deformation analysis of space frame is based on an Eulerian formulation, which takes into consideration the effects of large joint rotations with finite rotation. The local member force-deformation relationships are based on the beam-column approach, and the change in member chord lengths caused by axial strain and flexural bowing are taken into account. And the derived geometric stiffness matrix is asymmetric because of the fact that finite rotations are not commutative under addition. However the coupling effect of the member axial-torsional and warping effects are omitted. 


\subsection{Eulerian Formulation for Finite Rotation}

In the nonlinear analysis of space frames, the assumption that rotations of a body is additive has been widely adopted by researchers in updating the end rotations of frame elements at each incremental step. Such an assumption remains valid only for incremental steps with small rotations. For the cases with finite rotations, it is necessary to consider the non-commutative nature of rotations in three dimensions, such as post-buckling or bifurcation, which makes these space frames more difficult to analyze than trusses or plane frames in nonlinear analysis. In this paper, we used the previous work of Spiller [23] and Levy and Spiller [26] for the Eulerian finite rotation of 3D space frames, which is briefly described as follows.

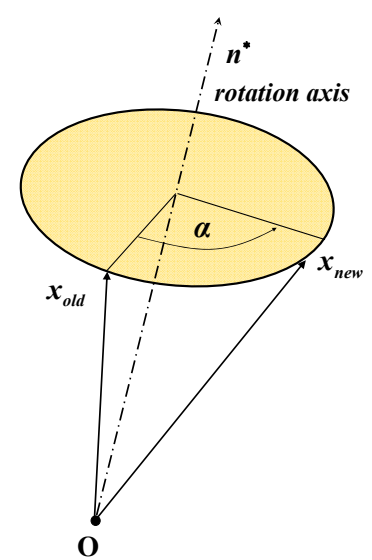

Figure 1. Rotation about an Axis

If an old position $\mathbf{x}_{\text {old }}$ of a body is rotated to new position $\mathbf{x}_{\text {new }}$, Euler's Theorem of rigid body motions implies that any finite rotation (or sequence of rotations) can be described as a single rotation $\alpha$ about some fixed axis described by a unit vector, $\mathbf{n}^{*}=\left\{n_{1}^{*}, n_{2}^{*}, n_{3}^{*}\right\}$, as shown in Figure 1. The new position vector $\mathbf{x}_{\text {new }}$ is described by the old position vector $\mathbf{x}_{\text {old }}$, the rotation $\alpha$ and the fixed axis unit vector $\mathbf{n}^{*}$ as follows:

$\mathbf{x}_{\text {new }}=\mathbf{x}_{\text {old }}-(1-\cos \alpha)\left\{\mathbf{x}_{\text {old }}-\left(\mathbf{x}_{\text {old }} \mathbf{n}^{*}\right) \mathbf{n}^{*}\right\}+\sin \alpha\left(\mathbf{n}^{*} \times \mathbf{x}_{\text {old }}\right)$

We can obtain the following matrix representation of finite rotations.

$\mathbf{x}_{\text {new }}=\widetilde{\mathbf{R}} \mathbf{x}_{\text {old }}$

$\mathbf{x}_{\text {old }}=\mathbf{R} \mathbf{x}_{\text {new }} \quad(\mathbf{R} \tilde{\mathbf{R}}=\mathbf{I})$

where $\mathbf{R}$ is the rotation matrix in terms of the $\alpha$ and the components of $\mathbf{n}^{*}$ as follows:

$$
\widetilde{\mathbf{R}}=\left[\begin{array}{ccc}
\cos \alpha+\mu n_{1}^{2} & -n_{3} \sin \alpha+\mu n_{1} n_{2} & n_{2} \sin \alpha+\mu n_{1} n_{3} \\
n_{3} \sin \alpha+\mu n_{1} n_{2} & \cos \alpha+\mu n_{2}^{2} & -n_{1} \sin \alpha+\mu n_{2} n_{3} \\
-n_{2} \sin \alpha+\mu n_{1} n_{3} & n_{1} \sin \alpha+\mu n_{2} n_{3} & \cos \alpha+\mu n_{3}^{2}
\end{array}\right]
$$

with $\mu=1-\cos \alpha$. 
Based on Euler's finite rotation formula, the rotation matrix is necessary to describe both joint rotations and member rigid body rotations. The matrix can be derived from the so-called Rodriguez rotation vector, a rotation about a fixed axis represented by a unit vector, and a scalar angle of rotation. Thus, a 3D rotation can be represented by a vector-like entity, but such entities cannot be added like vectors. Furthermore, it is assumed that these vector-like entities possess Taylor series expansions whose increments are the small rotation vectors of linear structural analysis [23, 26]. To separate the large rigid body deformation of a member from its relative deformation, which is assumed to be small, a Eulerian or local member coordinate system is used, as shown in Figure 2.

In Figure 2, the unit vector of the non-deformed member axis is $\mathbf{n}_{i}$, and the unit vector of the deformed member axis is $\mathbf{n}_{i}^{\prime}$.

Furthermore, the unit vectors of the deformed member axis at joints 1 and $2, \mathbf{n}_{1}^{*}$ and $\mathbf{n}_{2}^{*}$, can be represented by Euler's joint rotation matrices, $\mathbf{R}_{1}$ and $\widetilde{\mathbf{R}}_{2}$. The unit vector of the non-deformed member axis, $\mathbf{n}_{i}$, can be represented as follows.

$$
\begin{aligned}
& \mathbf{n}_{1}^{*}=\widetilde{\mathbf{R}}_{1} \mathbf{n}_{i} \\
& \mathbf{n}_{2}^{*}=\widetilde{\mathbf{R}}_{2} \mathbf{n}_{i}
\end{aligned}
$$

The rotation vector at joint 2, $\theta_{2}$, can be represented by the cross product of the member unit vector, $\mathbf{n}_{i}$, and the deformed member unit vector, $\mathbf{n}_{2}^{*}$, at joint 2 with properties as follows:

$$
\begin{aligned}
& \theta_{2} \cong \mathbf{n}_{i} \times \mathbf{n}_{2}^{*} \\
& \left|\theta_{2}\right|=\cos ^{-1}\left(\mathbf{n}_{i} \mathbf{n}_{2}^{*}\right)
\end{aligned}
$$

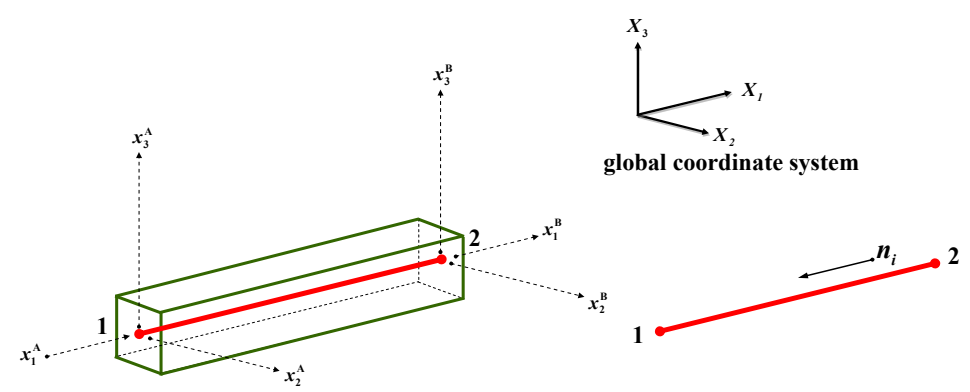

(a) Un-deformed member

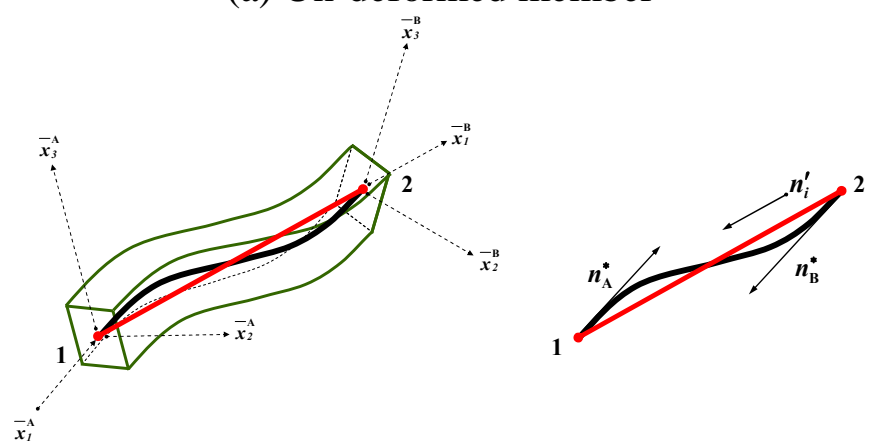

(b) Deformed member

Figure 2. Relative member deformations 
The end of member rotation vector for joint $1, \theta_{1}$, is represented as follows:

$\theta_{1}=\theta_{2}+\theta_{12}$

where $\theta_{12}$ is the rotation of joint 1 with respect to joint 2 . This equation simply describes the vector form of the matrix product, $\mathbf{R} \tilde{\mathbf{R}}_{2}$.

From this simple and exact formulation of Euler's finite rotation [23, 26], we can calculate the exact member end rotations, $\theta_{1}, \theta_{2}$ which separate the rigid body rotations. In the case of geometrically nonlinear large displacement analysis of space frame, the exact member rotational deformation is relatively small, because of its large rigid body rotation occurrence. The formulation of this study is valid for the elastic, elasto-plastic large deformation analysis of space frame element with beam-column equations. The accuracy and efficiency are demonstrated in verification examples lately.

\subsection{Beam-column Equation}

The member force of the space frame element shown in Figure 3 can be written by the 2D beam-column equations [22, 24, 25], which include the effect of member displacement upon the bending moment to the end. As a result, the member stiffness becomes a function of the axial load.

$$
\begin{aligned}
& M_{1 j}=\frac{E I_{j}}{L}\left(c_{1 j} \theta_{1 j}+c_{2 j} \theta_{2 j}\right) \quad(j=2,3) \\
& M_{2 j}=\frac{E I_{j}}{L}\left(c_{2 j} \theta_{1 j}+c_{1 j} \theta_{2 j}\right) \quad(j=2,3) \\
& M_{t}=\frac{G J}{L} \varphi_{t} \\
& Q=E A\left(\frac{u}{L}-\sum_{j=2}^{3} c_{b j}\right) \\
& c_{b j}=b_{1 j}\left(\theta_{1 j}+\theta_{2 j}\right)^{2}+b_{2 j}\left(\theta_{1 j}-\theta_{2 j}\right)^{2}
\end{aligned}
$$

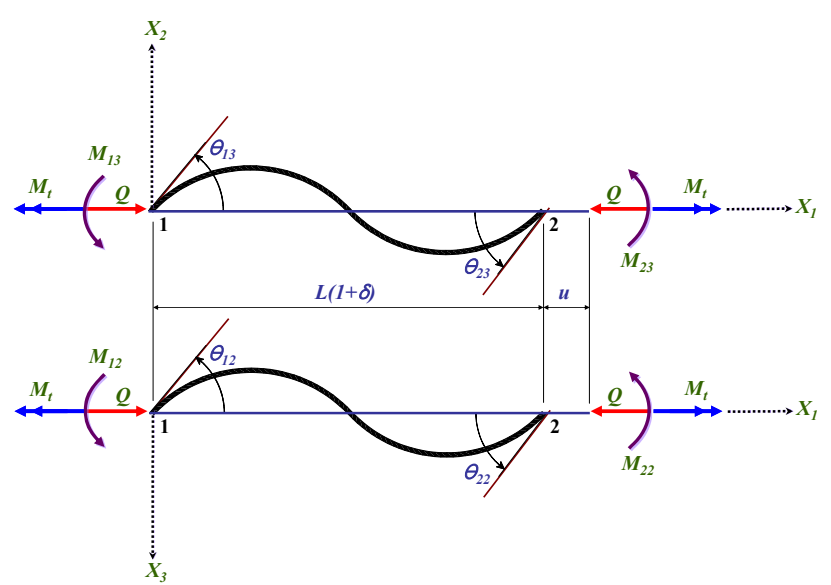

Figure 3. Relative Member Deformations and Corresponding Forces 
In above equations, $\theta_{1 j}$ and $\theta_{2 j}$ are the relative member end rotations calculated by Eqs. 35 and 37, where $\varphi_{t}$ is linear axial twist, $u$ is axial displacement, $A$ is the area of cross section, $E$ is the modulus of elasticity, $I_{j}$ is the moment of inertia about the $X_{j}$-axis, GJ is the torsional rigidity, $c_{1 j}$ and $c_{2 j}$ are the stability functions for bending about the $X_{j}$-axis, $c_{b j}$ is the length correction factor caused by flexural deformation (bowing) about the $X_{j}$-axis, and $b_{1 j}$ and $b_{2 j}$ are the bowing functions of the axial force parameter $q$, defined as follows.

$q=\frac{Q}{Q_{\text {Euler }}}=Q \frac{L^{2}}{\pi^{2} E I_{j}}$

The expression for the member axial force, $Q$ in Eq. 41 contains bowing functions $b_{1 j}$ and $b_{2 j}$, which are functions of the axial force parameter, $q$. Therefore, Eq. 41 is a nonlinear function. A computational difficulty arises in determining $Q$ from the axial displacement, $u$. An iterative procedure must be employed to compute the axial force of a member and can be solved using the following process. Noting that $q$ is the only unknown quantity in Eq. 41, let a new function, $K(q)$, be defined as follows:

$$
K(q)=\frac{\pi^{2}}{\lambda^{2}} q+\sum_{j=2}^{3} c_{b j}-\frac{u}{L}=0
$$

A new value of $q_{i+1}$ is obtained from the first order Taylor series expansion,

$$
q_{i+1}=q_{i}+\Delta q_{i}=q_{i}-\frac{K\left(q_{i}\right)}{K^{\prime}\left(q_{i}\right)}
$$

where $K^{\prime}(q)$ is the derivative of $K(q)$ with respect to the axial force parameter, $q$, and represented as follows:

$$
K^{\prime}(q)=\frac{d K(q)}{d q}=\frac{\pi^{2}}{\lambda^{2}}+\sum_{n=2,3}^{3} \frac{1}{\varepsilon_{j}}\left\{b_{1 j}^{\prime}\left(\theta_{1 j}+\theta_{2 j}\right)^{2}+b_{2 j}^{\prime}\left(\theta_{1 j}-\theta_{2 j}\right)^{2}\right\}
$$

where $\lambda=L / \sqrt{I / A}$ and $\varepsilon_{j}=I_{j} / I$, in which $I$ is an arbitrary reference moment of inertia and $b_{i j}^{\prime}$ is a differentiation of the bowing function with respect to $q$. An approximate solution to this equation for $q_{i}$ is initially assumed, and the iteration is performed until $\left|\Delta q_{i}\right|$ is sufficiently small. After determining the axial force $Q$ by the iterative process, member end moments were computed from Eqs. 38-40. Detailed description of Eqs. 38-46 and the corresponding variables are explained in references [22,24,25].

\subsection{Tangent Stiffness Matrix for Large Deformation}

In this study, the beam-column approach in section 6.2 is applied to elastic post-buckling, bifurcation problems. The non-commutative nature of finite rotation in section 6.1 yields an asymmetric tangent stiffness matrix in both cases. The member force-deformation relationships may be rewritten as follows: 


$$
\begin{aligned}
& \overline{\mathbf{s}}^{T}=\left\{Q, M_{t}, M_{12}, M_{13}, M_{22}, M_{23}\right\} \\
& \overline{\mathbf{u}}^{T}=\left\{u, \varphi_{t}, \theta_{12}, \theta_{13}, \theta_{22}, \theta_{23}\right\}
\end{aligned}
$$

And the incremental form of the member equation is written as follows:

$$
\Delta \overline{\mathbf{s}}=\mathbf{t} \Delta \overline{\mathbf{u}}
$$

Where $t$ is the element stiffness matrix according to the incremental member displacement $\Delta \overline{\mathbf{u}}$ in the local coordinates, as shown previously in Eqs. 38-41. By using the incidence matrix $\overline{\mathbf{B}}$, the element nodal force and nodal displacement can be written as follows:

$$
\begin{aligned}
\overline{\mathbf{d}} & =\overline{\mathbf{B}} \overline{\mathbf{u}} \\
\overline{\mathbf{f}} & =\overline{\mathbf{B}} \overline{\mathbf{s}}
\end{aligned}
$$

Conventionally, the element nodal force in global coordinates $\mathbf{F}$ can be written from the rotation matrix $\mathbf{R}$ :

$$
\mathbf{F}=\mathbf{R} \overline{\mathbf{f}}=\mathbf{R} \overline{\mathbf{B}} \overline{\mathbf{s}}
$$

Eq. 52 could be interpreted as a member equilibrium equation in a global coordinate system. The tangent stiffness matrix of the beam-column can be obtained from the differential form with respect to the incremental displacement $[23,26]$ :

$$
\begin{aligned}
& \Delta \mathbf{F}=\Delta(\mathbf{R} \overline{\mathbf{B}} \overline{\mathbf{s}})=\mathbf{R} \overline{\mathbf{B}}(\Delta \overline{\mathbf{s}})+\mathbf{R}(\Delta \overline{\mathbf{B}}) \overline{\mathbf{s}}+(\Delta \mathbf{R}) \overline{\mathbf{B}} \overline{\mathbf{s}} \\
& =\left(\mathbf{K}_{E}+\mathbf{K}_{G}^{S}+\mathbf{K}_{G}^{R}\right) \delta \mathbf{d}
\end{aligned}
$$

The first term in Eq. 53 becomes the elastic stiffness matrix. The second and third terms become the geometric stiffness matrix. $\mathbf{K}_{G}^{S}$ and $\mathbf{K}_{G}^{R}$ indicate the stretching and rotational terms of the geometric stiffness. The rotational geometric stiffness matrix, $\mathbf{K}_{G}^{R}$, is asymmetric [23,26,39] due to the non-commutative nature of finite rotation.

Several formulations have been proposed in the literature [39, 41-44] to improve the shortcomings of the cubic element and the conventional stability-based beam-column element. The improved formulation of co-rotational cubic elements by Teh and Clarke [39] used the asymmetric tangent stiffness matrix and shows more accurate results. Liew et al. [44] used the symmetric portion of the induced moment matrix alone, which is referred to as the joint moment matrix and needs to be assembled to form the structure tangent stiffness matrix. However the derived comprehensive asymmetric geometric stiffness matrix of Eq. 53 in this study is responsible for the lateral-torsional buckling and some symmetric and asymmetric buckling modes in physical situations at the critical bifurcation point to obtain accurate results as in the case of Teh and Clarke [39]. By performing some numerical examples of following sections, we will show the accuracy and efficiency of proposed bifurcation algorithm and element theorem. 


\section{VERIFICATON EXAMPLES}

In this section, the reported verification examples are analyzed by using the method of computational elastic bifurcation theory described above. Generally, the important research work of buckling classification of Thompson [2] is difficult to be applied to the actual problems, because which needs a diagonalized higher order derivative of energy function for classification criteria. However, by using the method of this study without considering higher order terms, eigen-value is used to classify the limit and bifurcation point buckling type, and is used to the path switching for primary and bifurcation path. Therefore the effectiveness and applicability of this study may be called as meaningful method. The following verification examples seem to be simple model, but they need amount of analytical efforts for numerical point of view.

\subsection{Example 1 : Multiple Bifurcation of Trussed Star-dome}

First verification example is the multiple bifurcation of trussed Star-dome [45]. After Hangai and Kawamata [45] reported the results, Star-dome became a representative verification example for buckling analysis which composed with trussed element. The reason that the trussed dome structure, Star-dome, is frequently used for the highly nonlinear buckling analysis is as follows. The truss element is most simple and easy to formulate in FEM analysis, the FE formulated nonlinear equilibrium equation of truss element shows the exact solution. And complex post buckling behaviors are presented relatively easy and clear with trussed element.

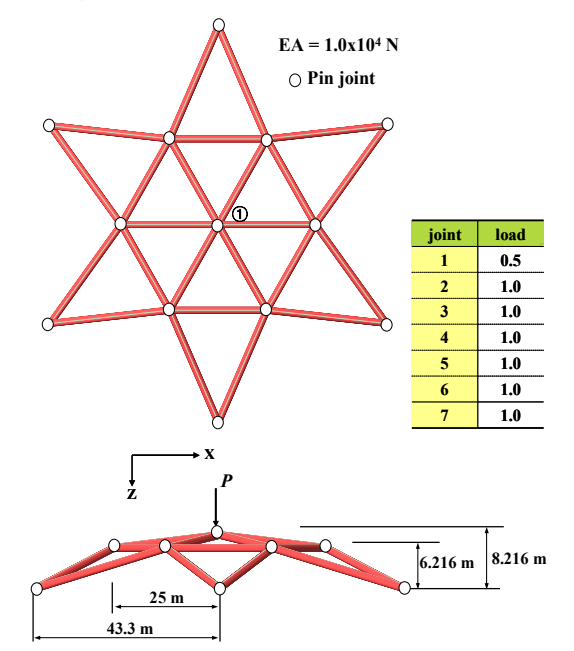

Figure 4. Star-dome : Geometry and Load Condition

To verify the accuracy and applicability, the post buckling bifurcation analysis is performed by using the proposed approach. Figure 4 illustrates the model for geometry and loading conditions. The boundary condition for Star-dome is pin support. Figure 5 illustrates the load-deflection curves for primary and bifurcation path at apex before first limit point. As shown in Figure 5, three bifurcation points are detected before the first limit point. In Figure 5, BP1, BP2, BP3 are bifurcation point and LP1 is limit point. Among bifurcation points, BP2, BP3 show the characteristics of multiple bifurcation point. The load parameters of each critical point in Figure 5, are described in Table 1 with the results of previous research works. The results buckling load parameters obtained using the proposed approaches are in good agreement with references $[10,13]$. In Table 2, the eigen-values and corresponding arc-lengths for each bifurcation and limit point are described. 


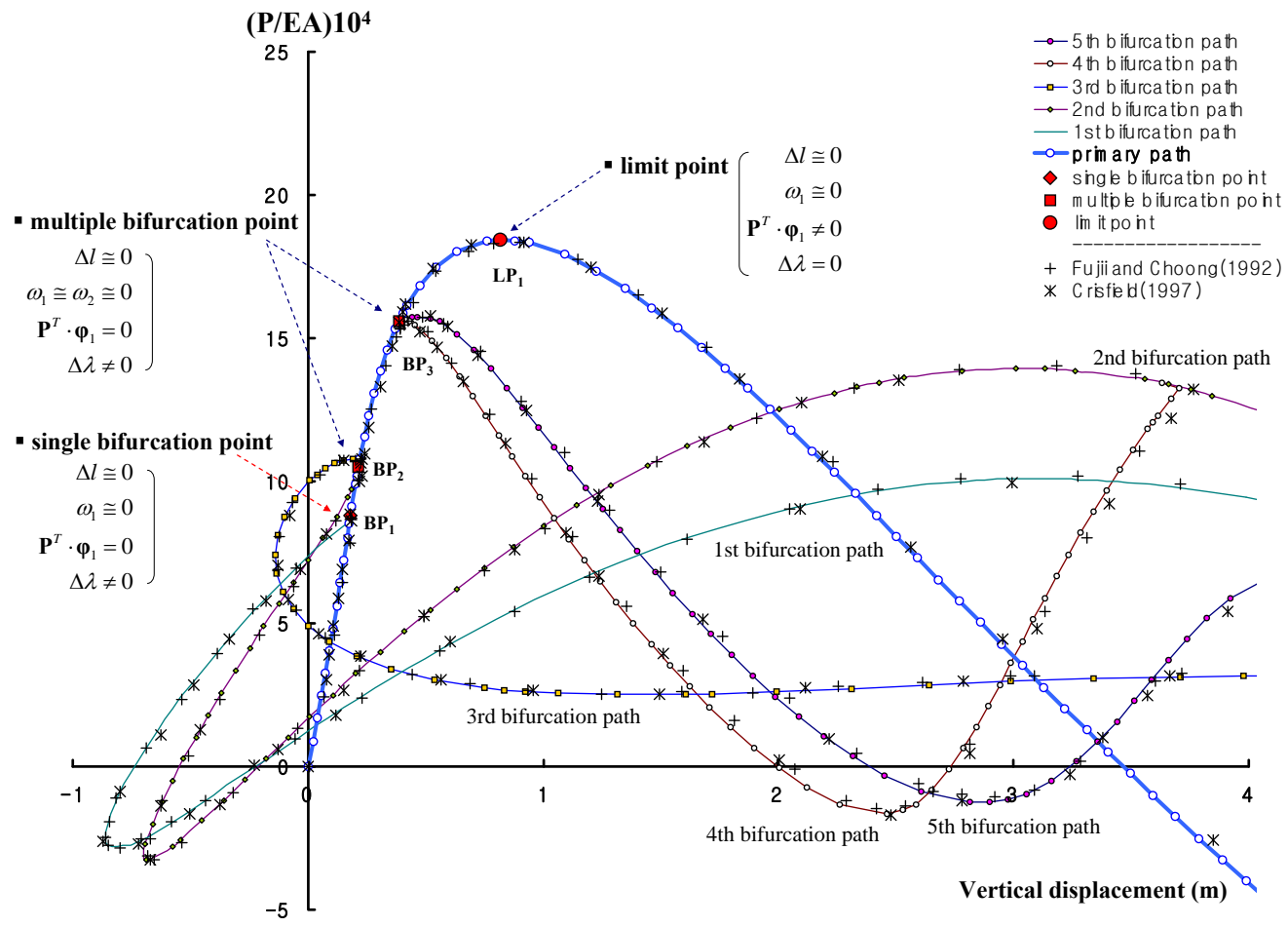

Figure 5. Star-dome: Primary and Bifurcation Paths, Deterministic Equation for Bifurcation Point

At critical points, BP1, BP2, BP3, LP1, the corresponding smallest non-negative eigen-values are nearly zero as described in Figure 5 and Table 2. We can distinguish the bifurcation and limit point by using Eq. 16. If $\mathbf{P}^{T} \boldsymbol{\varphi}_{1}=0$ and $\Delta \lambda=0$, the point is bifurcation point. Otherwise $\mathbf{P}^{T} \boldsymbol{\varphi}_{1} \neq 0$ and $\Delta \lambda=0$, the point is limit point. As described in Figure 5 and Table 2, if multiple number of eigen-value is non-negative nearly zero or zero, the point is multiple bifurcation point. If single number of eigen-value is non-negative nearly zero or zero, the point is single bifurcation point. The deterministic parameter, arc-length calculated by using Eq. 26 is related the smallest non-negative eigen-value of Table 2. When the point is critical, the corresponding eigen-value and its arc-length present also critical value.

If the path switching is performed at particular bifurcation point, the corresponding smallest eigen-vector is used for the bifurcation mode in Eq. 28. Accurate representative bifurcation mode is satisfied by using the eigen vector only in this study. By using the algorithm of this study, just using the re-ordered the eigen-value for detection and corresponding eigen-vector for path switching, the resulting primary and bifurcation paths of this paper as described in Figure 5 are in good agreement with reference [10,13]. The additional process is minimized unlike reference $[3,10,13]$. The preparation of particular mode [3] or trial error [10] or combination of eigen-vector is not required.

Figure 6 illustrates the load-deflection curve of primary path and corresponding deformed shape of Star-dome after first limit point. It can be seen that there are eight limit points and fourteen bifurcation points in the primary path. The final resulting deformed shape at "(10)" is inversed configuration of initial shape. The load-deflection curve of primary path and its corresponding deformed shape is exactly symmetric about vertical axis. If some perturbations may be imposed to the system at each single or multiple bifurcation points, the structure may loose the symmetric and perfect status, and the system will branch to the bifurcation path. 
Table 1. Load Parameters at Critical Points

\begin{tabular}{|l|l|l|l|l|}
\hline & BP1 & BP2 & BP3 & LP1 \\
\hline Present & 8.700 & 10.282 & 15.662 & 18.420 \\
\hline Fujii and Choong[13] & 8.689 & 10.267 & 15.606 & - \\
\hline Crisfield[10] & 8.680 & 10.260 & 15.670 & 18.400 \\
\hline
\end{tabular}

Table 2. Non-negative Smallest Eigen-value at Critical Points

\begin{tabular}{|c|c|c|c|c|c|c|c|c|c|c|c|c|c|}
\hline & \multicolumn{3}{|c|}{ BP1(sigle) } & \multicolumn{3}{|c|}{ BP2(multiple) } & \multicolumn{3}{|c|}{ BP3(multiple) } & \multicolumn{3}{|l|}{ LP1 } & \\
\hline no. & \multicolumn{2}{|c|}{ eigen-value } & $\begin{array}{l}\text { arc } \\
\text { length }\end{array}$ & \multirow{2}{*}{\multicolumn{2}{|c|}{$\begin{array}{l}\text { eigen-value } \\
-2.0257\end{array}$}} & $\begin{array}{l}\text { arc } \\
\text { length }\end{array}$ & \multicolumn{2}{|c|}{ eigen-value } & $\begin{array}{l}\text { arc } \\
\text { length }\end{array}$ & \multicolumn{2}{|c|}{ eigen-value } & \multicolumn{2}{|l|}{$\begin{array}{l}\text { arc } \\
\text { length }\end{array}$} \\
\hline 1 & 0.0063 & $1 \mathrm{st}$ & 0.0123 & & & & -10.5388 & & & -20.21667 & & & 1st bif. \\
\hline 2 & 1.7978 & & & 0.0028 & $1 \mathrm{st}$ & (19191 & -7.4349 & & & -15.70293 & & & 2nd bif. \\
\hline 3 & 1.7978 & & & 0.0028 & 2nd & 0.0191 & -7.4349 & & & -15.70293 & & & 3rd bif. \\
\hline 4 & 5.6434 & & & 4.5836 & & & 0.0023 & $1 \mathrm{st}$ & 00054 & -5.77217 & & & 4th bif. \\
\hline 5 & 5.6434 & & & 4.5836 & & & 0.0023 & 2nd & 0.0054 & -5.77217 & & & 5th bif. \\
\hline 6 & 10.0432 & & & 9.5359 & & & 5.3882 & & & 0.00446 & $1 \mathrm{st}$ & 0.00609 & \\
\hline 7 & 12.9365 & & & 13.5073 & & & 19.7080 & & & 30.83958 & & & \\
\hline 8 & 235.8343 & & & $235.601 €$ & & & 234.7680 & & & 234.22004 & & & \\
\hline 9 & 235.8343 & & & $235.601 €$ & & & 234.7680 & & & 234.22004 & & & \\
\hline 10 & 397.4360 & & & 397.7181 & & & 398.9116 & & & 400.36883 & & & \\
\hline
\end{tabular}

Figures 7-11 illustrate the primary and bifurcation paths of load-deflection curves at each BP1, BP2, BP3 points in Figure 4. Each bifurcation paths are plotted inside the boundary of primary path. Any bifurcation paths do not deviate the boundary of primary path significantly. Because the motion of bifurcated system which losses the symmetry, will return to the primary path in to obtain the symmetry, the exact prediction of primary path is the most important factor of prerequisites in bifurcation analysis. And the bifurcation buckling may be understood as the unstable structural state loosing symmetry and imperfection imposed system. The simple and efficient numerical process of this study enables the analysis of path tracing, detecting critical point and path switching with high accuracy.
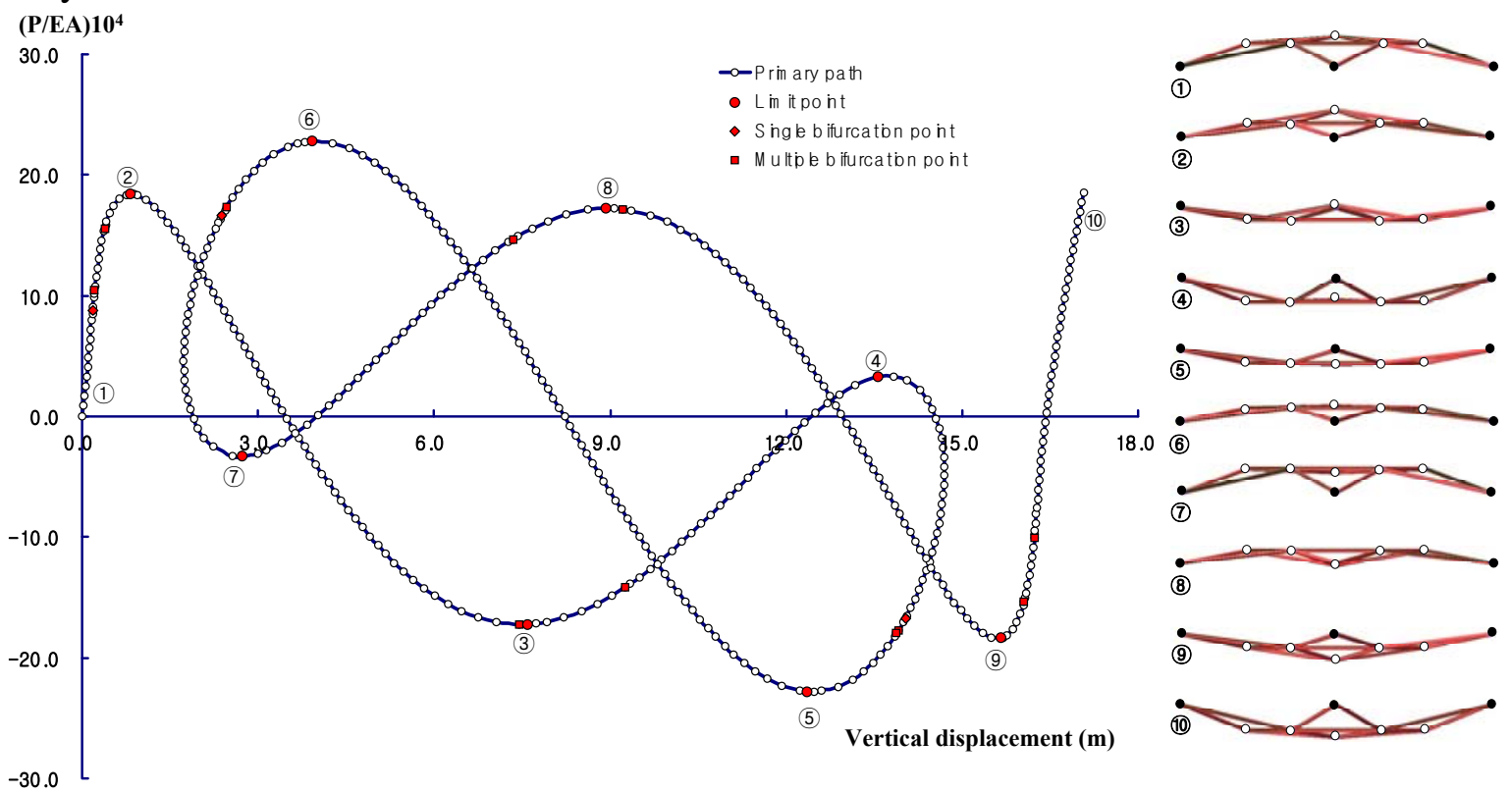

Figure 6. Star-dome : primary path and corresponding deformed shape at apex 


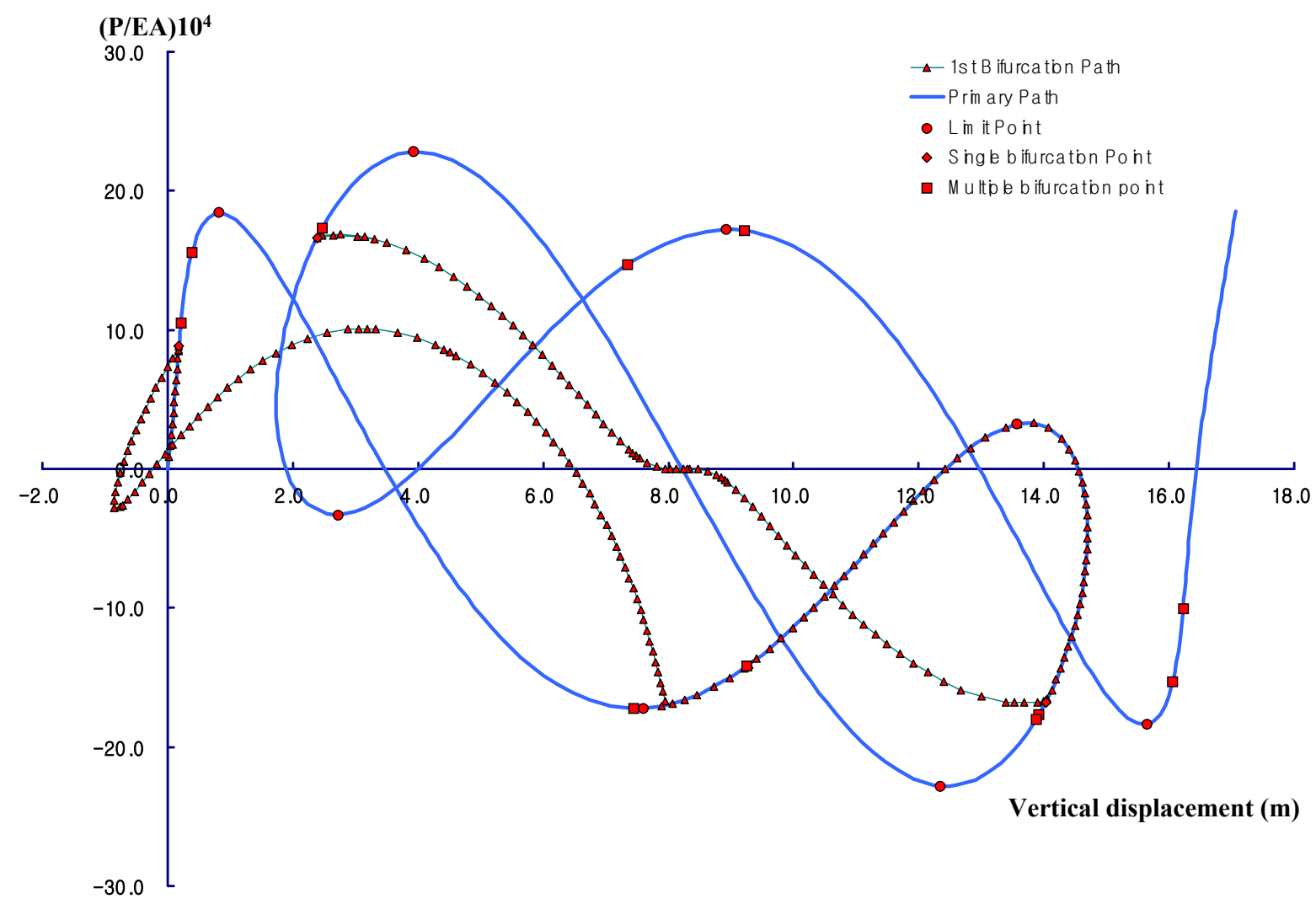

Figure 7. Star-dome : Primary and 1st Bifurcation Path at Apex

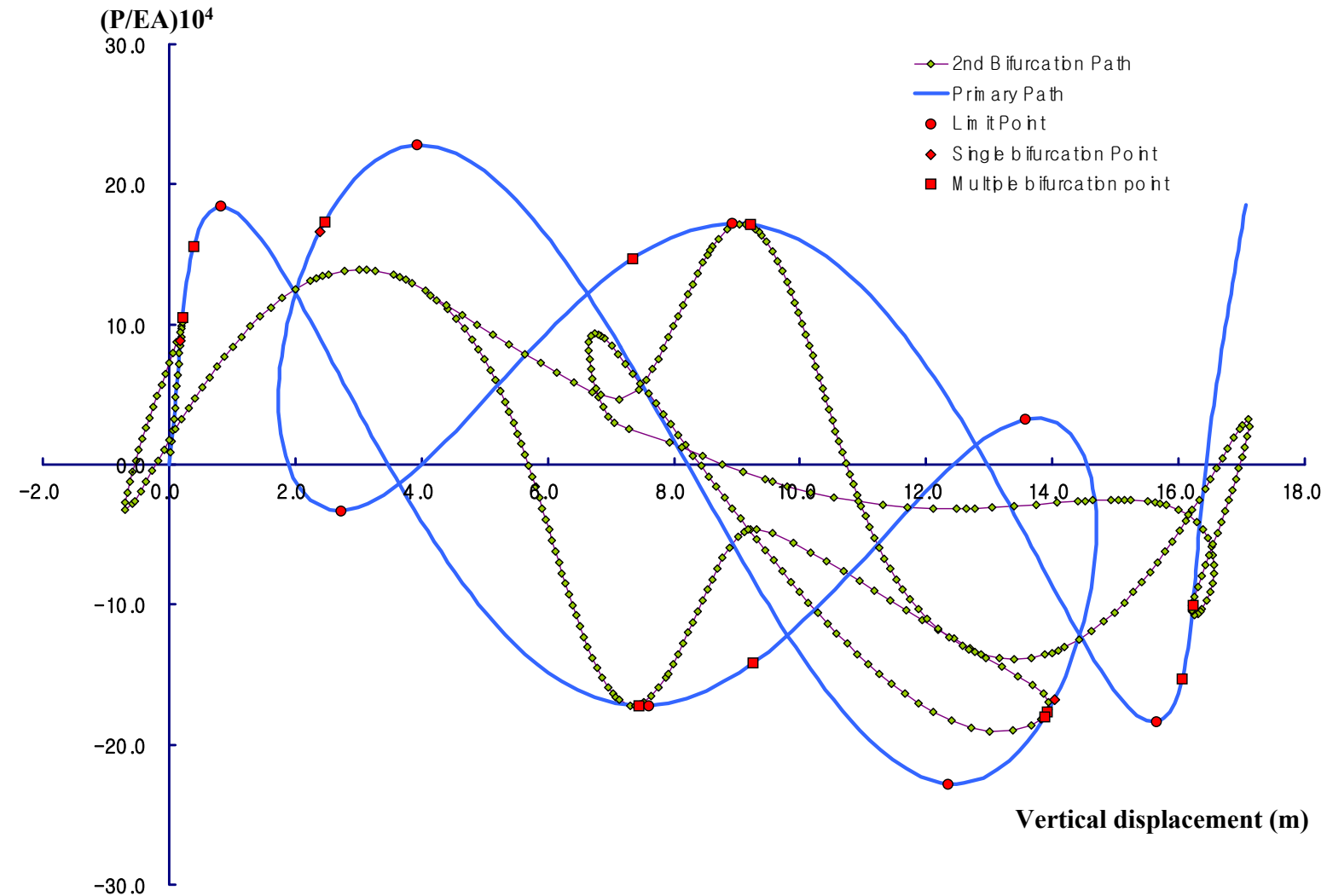

Figure 8. Star-dome : Primary and 2nd Bifurcation Path at Apex 


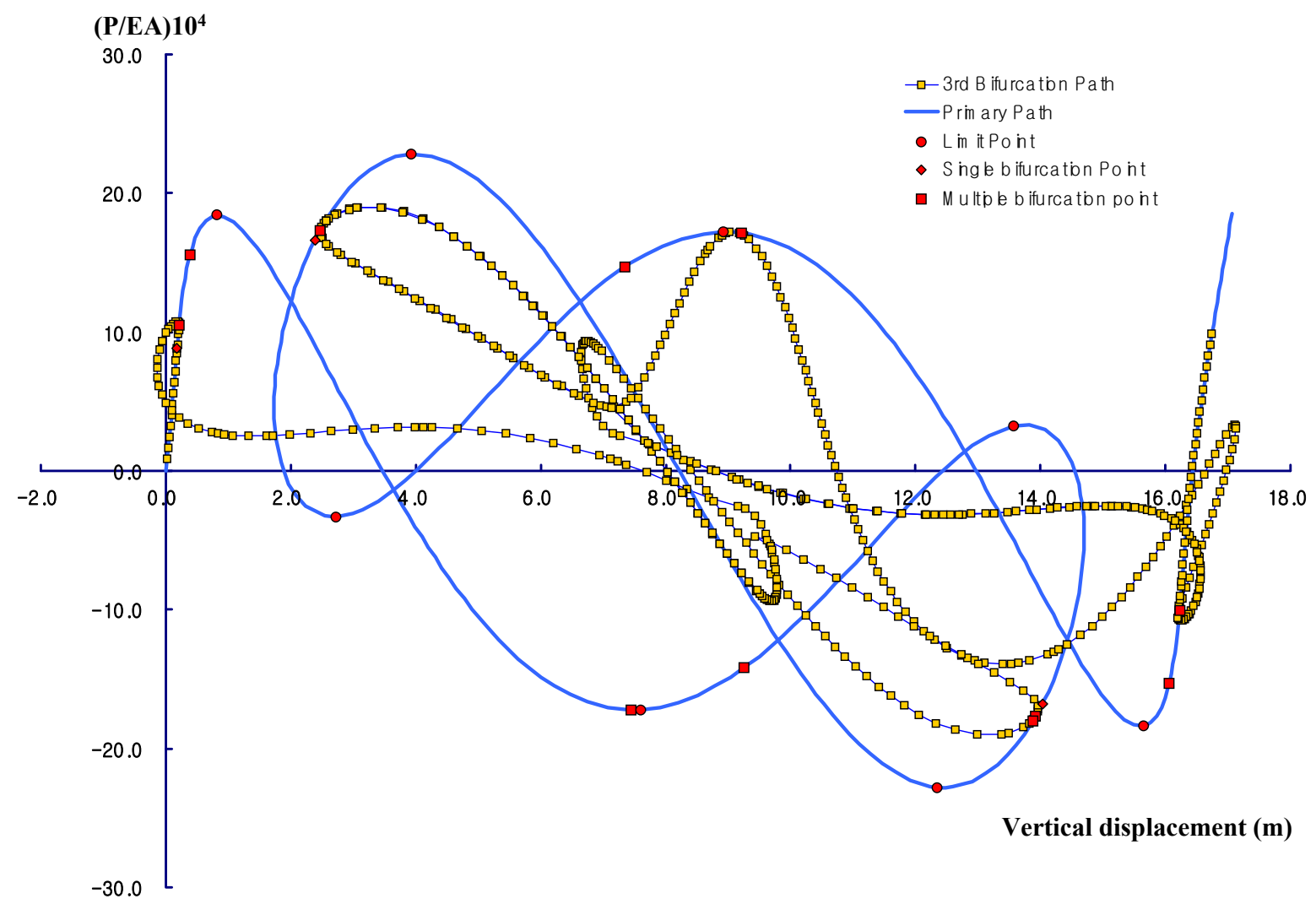

Figure 9. Star-dome : : Primary and 3rd Bifurcation Path at Apex

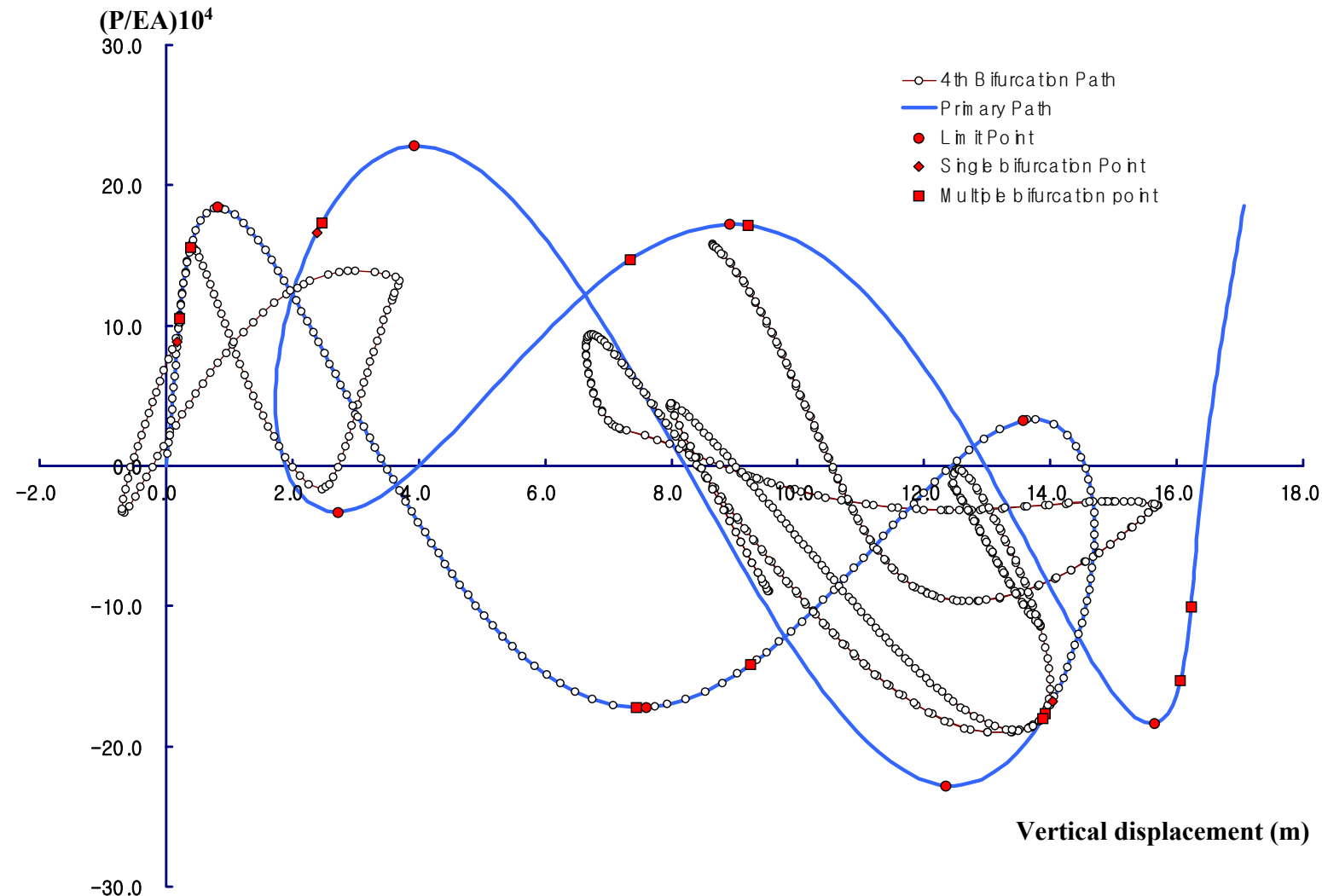

Figure 10. Star-dome : : Primary and 4th Bifurcation Path at Apex 


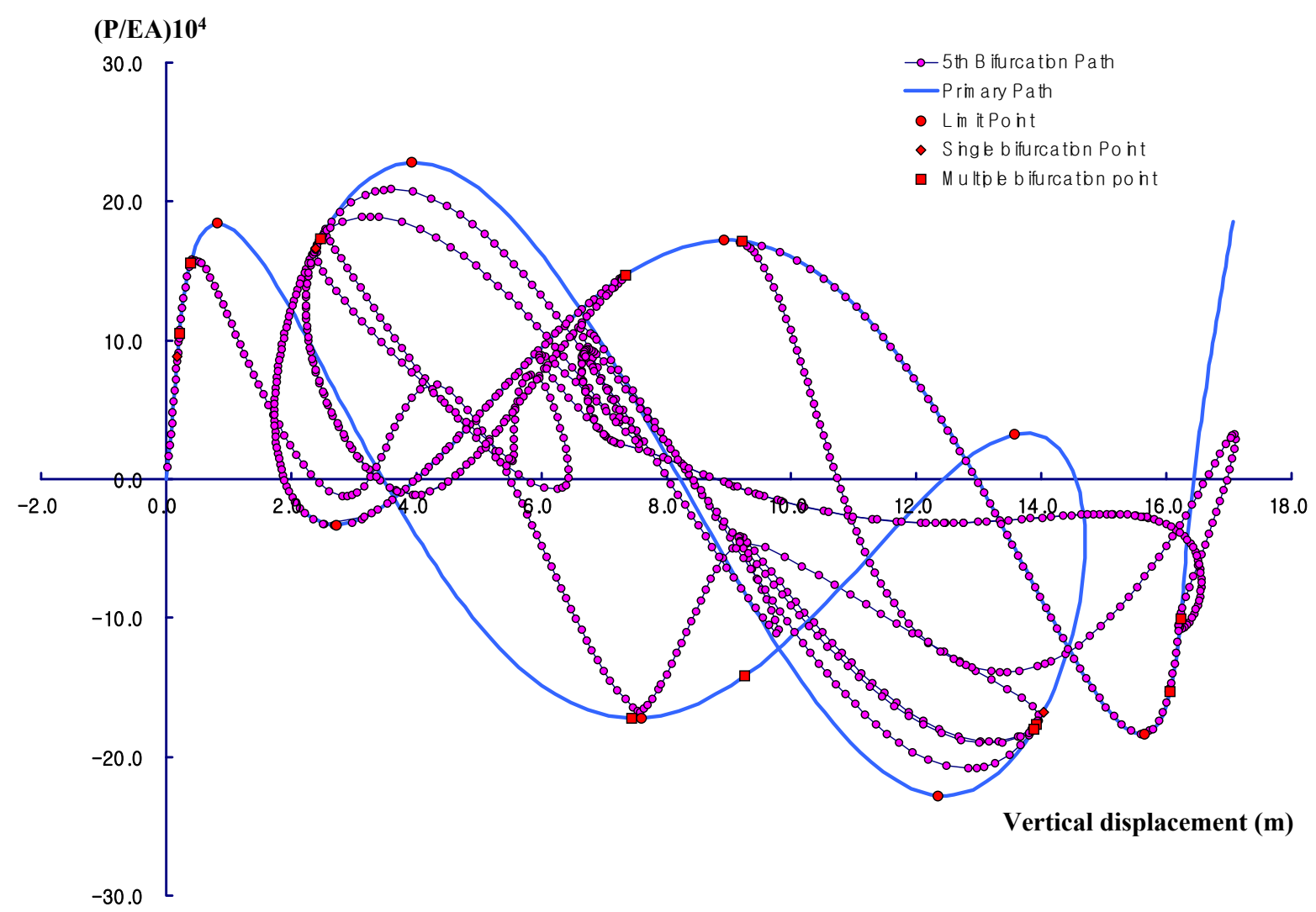

Figure 11. Star-dome : : Primary and 5th Bifurcation Path at Apex

\subsection{Example 2 : Bifurcation of Plane arch with Geometric Imperfections}

As shown in Figure 12, simple plane arch, which is modeled by 10 straight beam-column element of this study as the same of references [48], is analyzed to obtain the primary and bifurcation equilibrium path, and compared with previous reported results. The resulting equilibrium paths and limit points of two imperfections are illustrated in Figures 12 and 13. Figure 12 shows the load-deflection curves and deformed shape of this example which was analysis by Hosono [3] and Sabir and Lock [46]. Likewise the result of Star-dome model, the primary equilibrium path is the result of perfect and symmetric motion of system. However the deformed shape of bifurcation path, Figure 12, (b) represents the asymmetry and imperfect behavior. When geometrical imperfections are imposed to the system, the asymmetric motions occur and the resulting load-deflection curves are turned down before first bifurcation point BP1. Full load deflection curves are plotted in Figure 13.

Sabir and Lock [46] proposed the equilibrium primary and first bifurcation path by using FEM based displacement increment method. Hosono [3] analyzed the model by using beam element of Powell [47] and arc-length method. Previously, they reported only single, first bifurcation path which connect bifurcation point, BP1-BP4 in Figure 13. None reported second bifurcation path which connect bifurcation point, BP2-BP3. However the result of our bifurcation analysis, due to the correct bifurcation mode of eigen value analysis, which used the asymmetric tangent stiffness matrix of Eq. 57 and geometric large deformational formulation of Eulerian finite rotation, searched un-reported second bifurcation path successfully. 


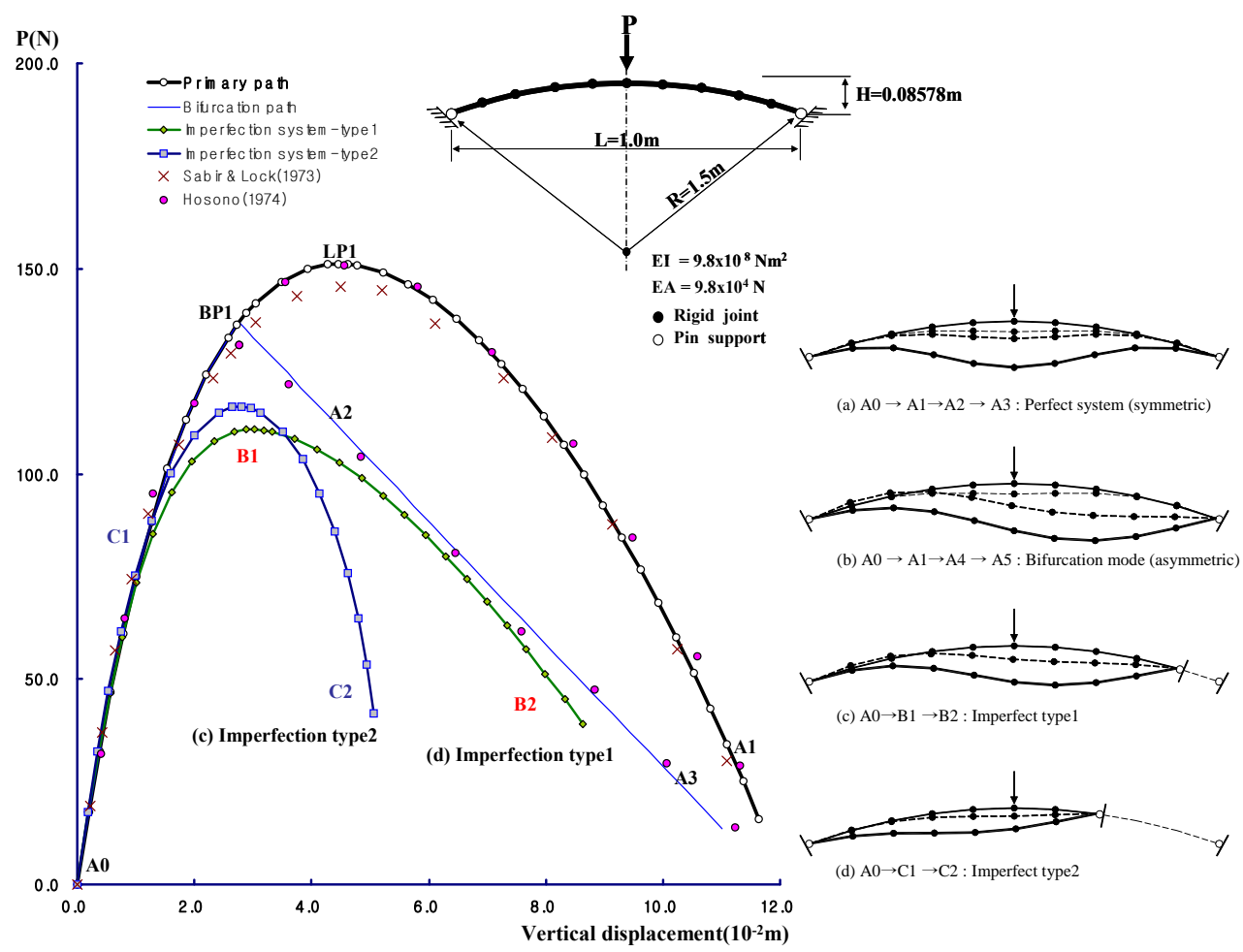

Figure 12. Plane Arch : Geometry, Load-deflection Curves and Corresponding Deformed Shape

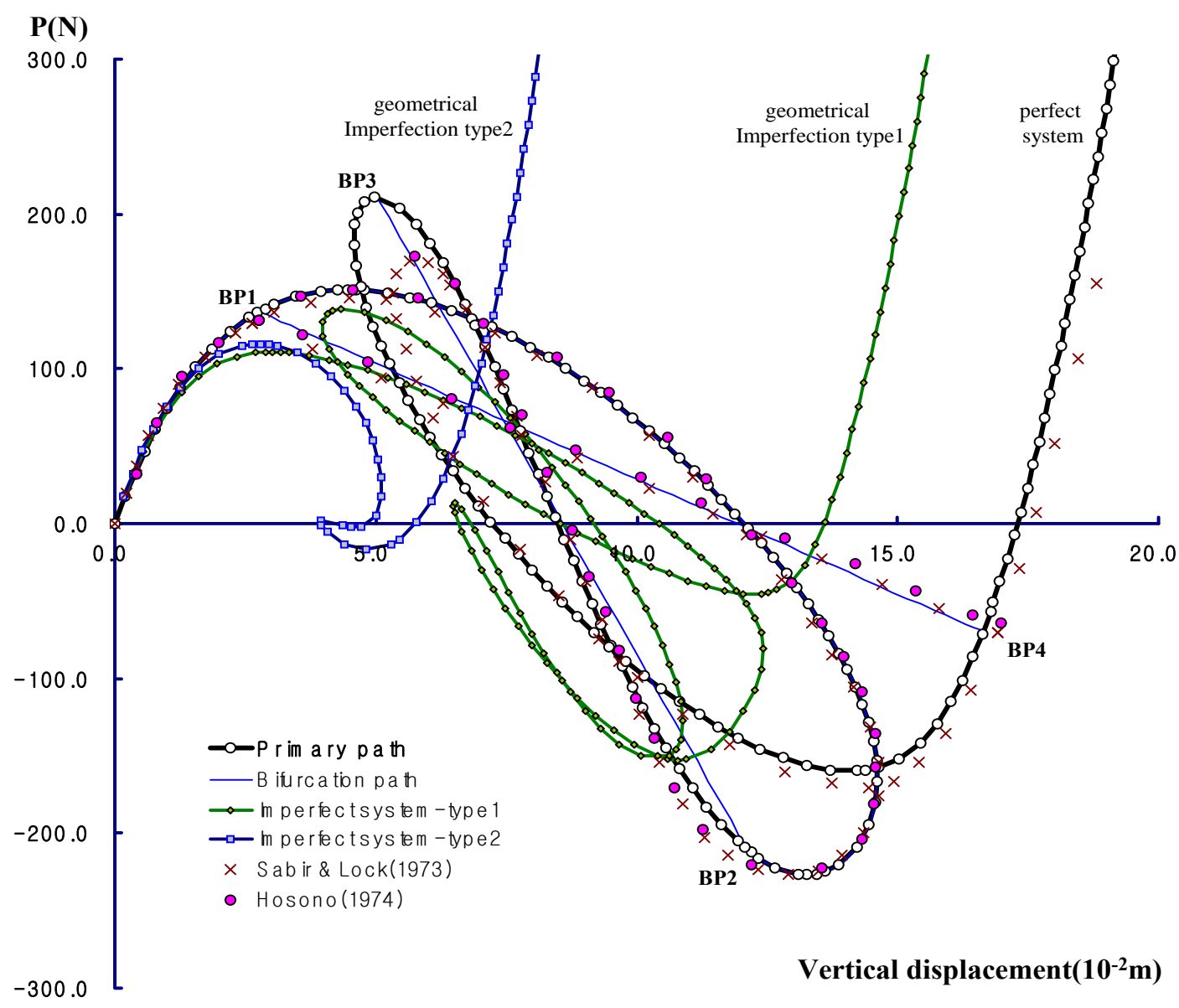

Figure 13. Plane Arch : Load-deflection Curves for each Loading Conditions 


\subsection{Example 3 : Bifurcation of Plane Frame}

Fujii and Ramm [18] reported the equilibrium primary and three bifurcation paths previously. The result of bifurcation for plane frame, as shown in Figure 14, is compared with that of Fujii and Ramm [18]. As shown in Figure 14, the results of our studies are in good agreement with reported results for the shape of load-deflection curves with 5-element per member as the same as reference [18]. However there are some differences for the load parameters, because of the difference of adopted beam element theory. The Eulerian finite rotation formulation of our study enables the buckling analysis to be geometrically large deformational analysis exactly. As shown in Figure 14, three branched equilibrium bifurcation paths are returned to the symmetric primary path at bifurcation points, BP4, BP5 and BP6. These results explain the excellent performance of the theory of this paper for rigid body motion of large deformation in beam-column element theory and joint finite rotation. Eigen-modes obtained from asymmetric tangent stiffness are displaced in Figure 14, and are used for branch switch to bifurcation path. The overall processes of our studies for bifurcation analysis perform well without any difficulties.

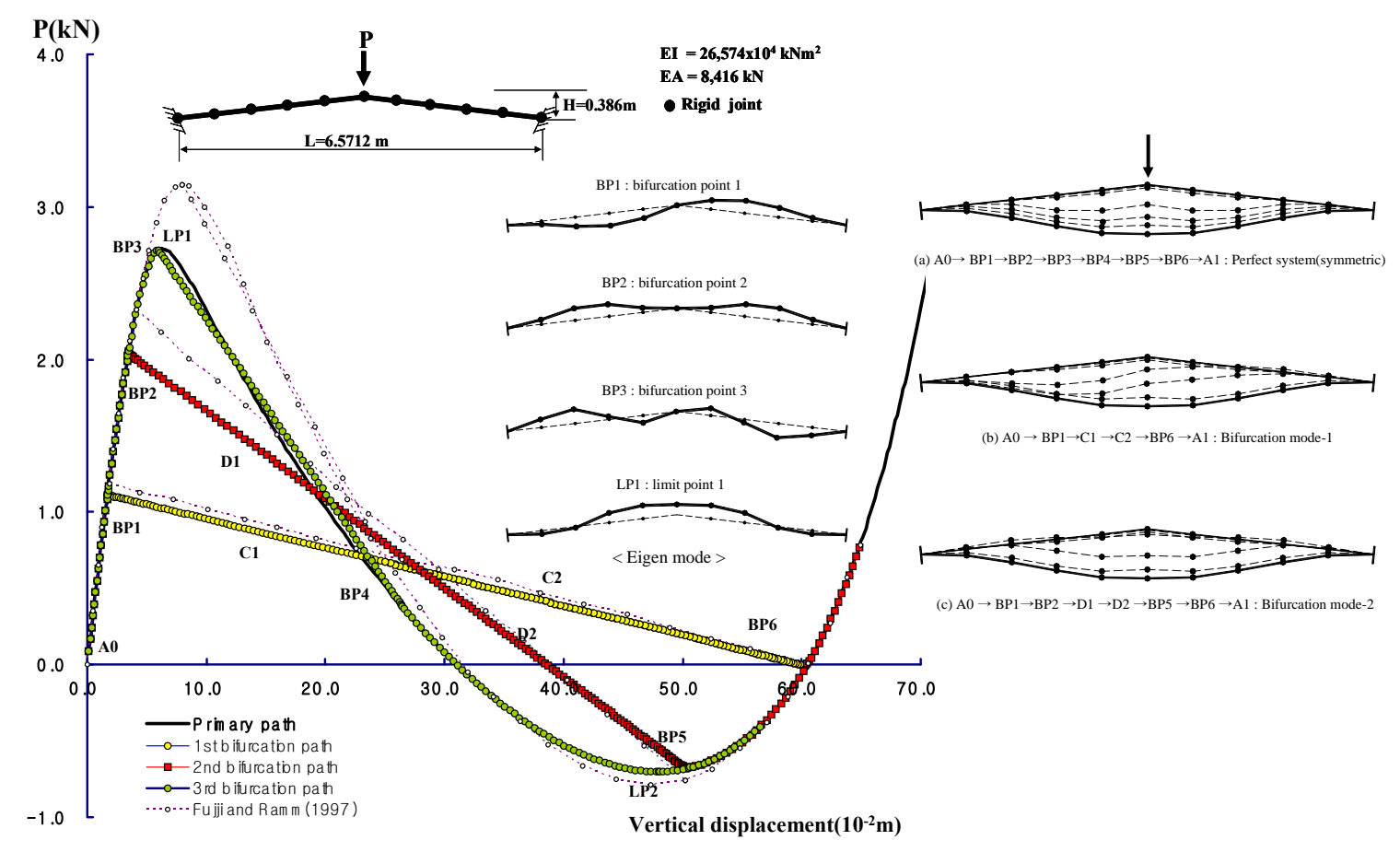

Figure 14. Plane Frame : Load-deflection Curves and Deformed Shape

\subsection{Example 4 : Bifurcation of Space Dome}

To verify the accuracy and applicability of the proposed beam-column element and stability theory to the 3D framed structure, space dome model, as shown in Figure 15, was performed. The loading case is divided as distributed and concentrated. Figure 16 illustrated the load-deflection curves for each loading condition as described in Figure 15. When the distributed loads are applied, the bifurcation buckling occurs. Otherwise the snap-through buckling may occur when the concentrated load is applied as shown in Figure 16. As described in references [24,48,50,51], the analysis is performed by 1 element per member. However Papadrakakis and Ghionis [49] performed this example with FE formulated 4 element/member. In general, the more number of elements per member is essential when $\mathrm{FE}$ beam element is used. 

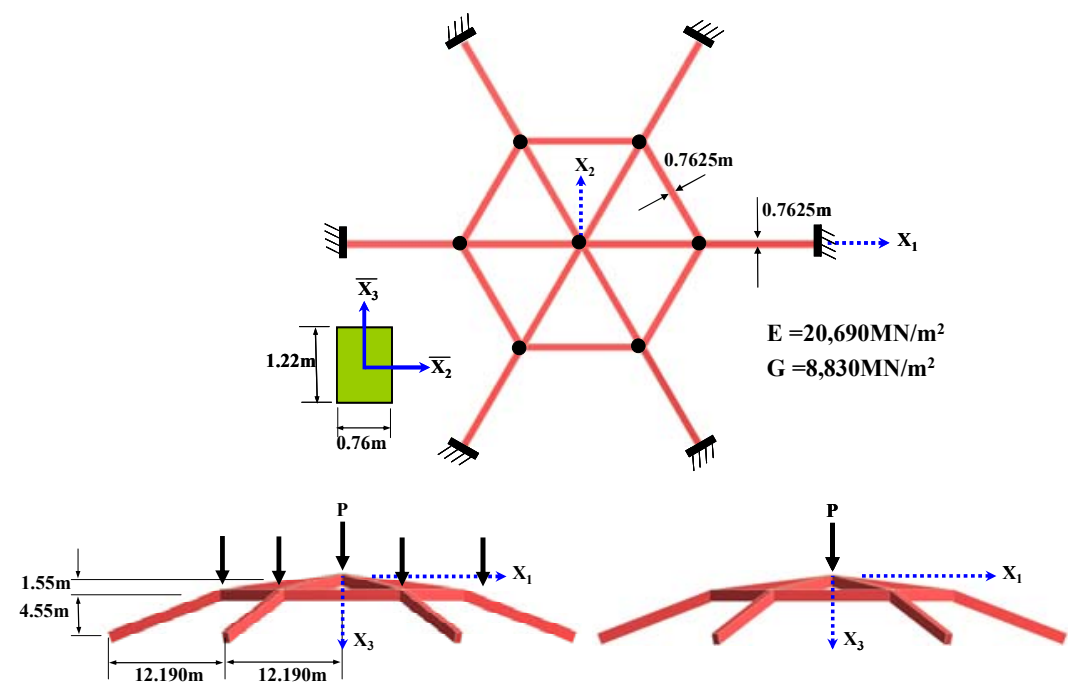

(a) distributed loads

(b) concentrated load

Figure 15. Space Dome: Geometry and Load Case

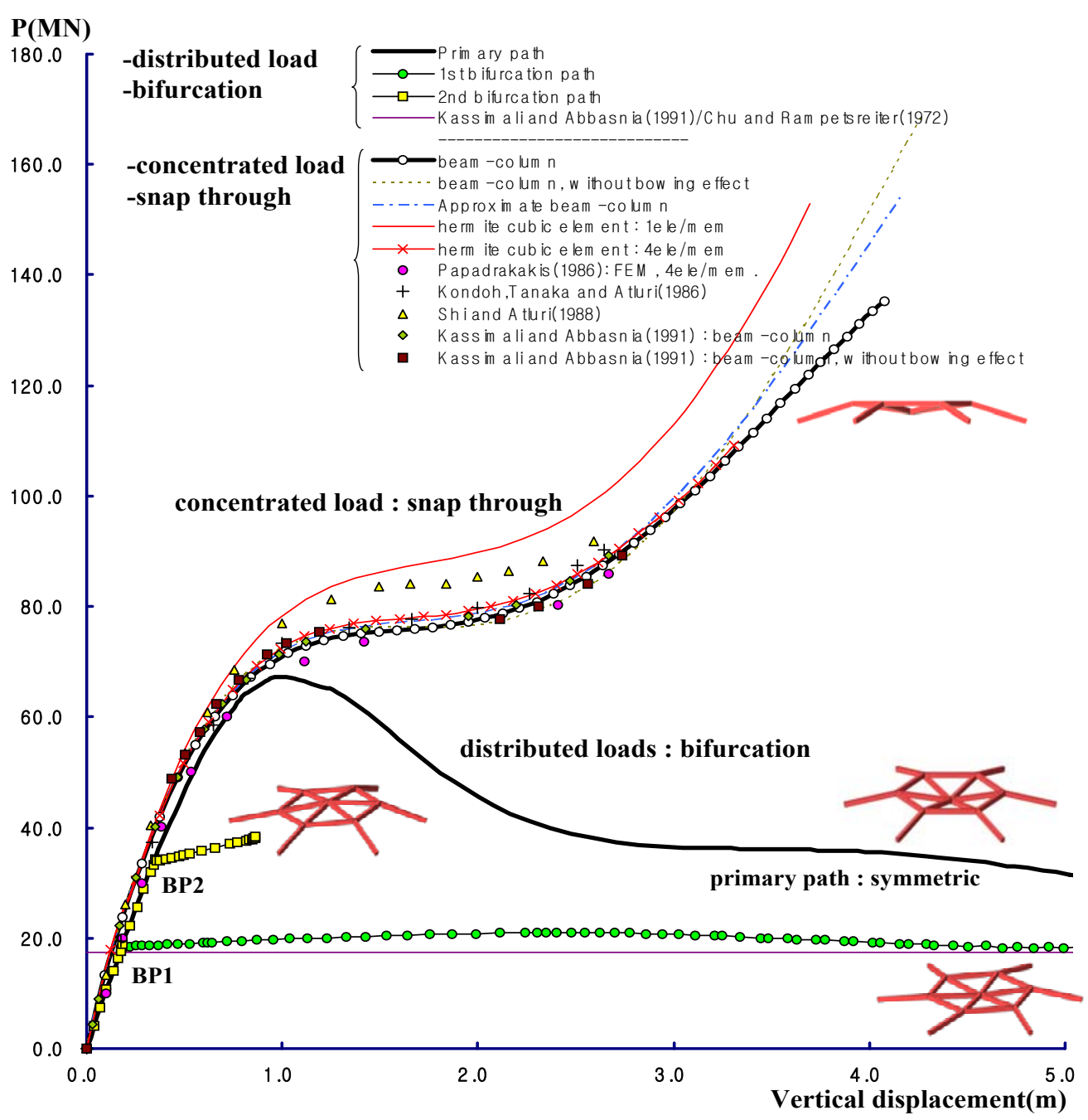

Figure 16. Space Dome: Load-deflection Curves 


\section{CONCLUSIONS}

In this study, the bifurcation analysis for plane and space frame is performed by using the proposed numerical method and Eulerian formulated large deformational beam-column element theory. The simple and efficient indirect method is used to identify the characteristics of critical point through the calculation of parametric variables determined by the smallest eigen-value without considering the higher order terms in equilibrium equation. And these smallest eigen value and corresponding eigen vector are used to analysis both single and multiple bifurcation buckling cases. To account for the geometrical nonlinear of large deformational rigid body motion of space frame element for post buckling bifurcation analysis, Eulerian finite rotation and beam-column equations with bowing effect are developed based on previous proposed theories. As a result of adopted geometrically nonlinear element formulation, the tangent stiffness matrix is asymmetric [23, 26]. However the resulting eigen values and corresponding eigen modes based on the asymmetric tangent stiffness matrix do good performance for bifurcation analysis with efficient bifurcation theories of this study. The good agreement and superior performance of verification examples indicate that the adopted numerical method and element theory are worthy to consider for bifurcation and post buckling analysis.

In case concentrated load is applied, the resulting curves of this study by using 1 number of beam-column element with bowing effect and finite rotation shows good agreement with references. When the hermite cubic beam element is used, at least $4 \mathrm{FE}$ element is required for the accuracy as in the case of Paradrakakis and Ghionis [49]. The approximate beam-column in Figure 16 represents the element formulation of using the approximate beam-column equation of Eqs. 47-50. In spite of approximated equations, the resulting curve of approximate beam-column element shows good performance compared with hermite cubic and beam-column element without bowing effect.

When the distributed loads are applied, Kassimali and Abbasnia [24] and Chu and Rampetsreiter [48] reported the buckling load value as $17.355 \mathrm{kN}$ and $17.413 \mathrm{kN}$ by using the eigen value analysis respectively with their symmetric tangent stiffness but the bifurcation path is not presented. In our study, the load parameter of first bifurcation point is $17.400 \mathrm{kN}$, therefore it can be seen that the first buckling load value of our study is in good agreement with references [48,24]. As shown in Figure 16, the nearly linear behavior is obtained until first limit point, LP1. The bifurcation point BP1 and BP2 are detected from the eigen value analysis with asymmetric tangent stiffness matrix of our study. The bifurcation modes in Figure 16 are conjugated with the deformed shape of structure. Therefore it can be understood that the motion of bifurcations are dependent with the bifurcation, eigen modes and tangent stiffness matrix. From the result of this example, it can be said that the large deformational Eulerian formulation of our study with asymmetric tangent stiffness may do good performance for 3D space frame to the highly nonlinear pre/post buckling analysis, path tracing, path switching, detection of critical points.

\section{ACKNOWLEDGEMENTS}

This research was supported by a grant (code\#'09 R\&D A01) from Cutting-edge Urban Development Program funded by the Ministry of Land, Transport and Maritime Affairs of Korean government and also supported by INHA UNIVERSITY Research Grant. 


\section{REFERENCES}

[1] Koiter, W.T., “On the Stability of Elastic Equilibrium”, Thesis, Polytechnic Institute, Delft H.T., Paris, Amsterdam, 1945.

[2] Thompson, J.M.T. and Hunt. G.W., “A General Theory of Elastic Stability”, John Wiley \& Sons, Chichester, UK, 1973.

[3] Hosono, "The Analysis of Elastic Buckling Problem by using the Arc-length Method", Thesis, Tokyo University, 1974.

[4] Riks, E., “An Incremental Approach to the Solution of Snapping and Buckling Problems”, Interna. J. Solids Structures, 1979, Vol. 15, pp. 529-551.

[5] Riks, E., "Some Computational Aspects of the Stability Analysis of Nonlinear Structures", Comput. Methods Appl. Mech. Engrg., 1984, Vol. 47, pp. 219-259.

[6] Crisfield, M.A., "A Fast Inremental Iterative Solution Procedure that Handles 'snap through'”, Computer \& Structures, 1981, Vol. 13 pp. 55-62.

[7] Ramm, E., "Strategies for Tracing the Non-linear Response near Limit Points”, in Nonlinear Finite Element Analysis in Structural Mechanic, Wunderlich, W. et al. Eds., Springer-Verlag. Berlin, 1981, pp. 63-89.

[8] Crisfield, M.A., “An Arc-length Method Including Line Searches and Accelerations”, Int. J. Num. Meth. Eng., 1982, Vol. 19, pp. 1269-1289.

[9] Crisfield, M.A. and Shi, J., "A Review of Solution Procedures and Path-following Techniques in Relation to the Non-linear Finite Element Analysis of Structures”, Nonlinear Computational Mechanics: State of the Art, Edited by Wriggers, P. and Wagner, W. Eds., Springer-Verlag, Berlin, 1990, pp. 47-68.

[10] Crisfield, M.A., "Nonliear Finite Element Analysis of Solids and Structures”, Vol. 2, Advanced Topics, John Wiley \& Sons, 1997.

[11] Choong, K.K. and Hangai, Y., "Review on Methods of Bilurcation Analysis for Geometrically Nonlinear Structures”, Int. Assoc. Shells Spatial Struct. (Issue Dedicated to SE1KEN-IASS Symposiunl on Nonlinear Analysis and Design for Shell and Spatial Structures), 1993, Vol. 34, No. 2, pp. 133-149.

[12] Wagner, W. and Wriggers, P., "A Simple Method for the Calculation of Postcritical Branches”, Engng. Comput., 1988, Vol. 5, pp. 103-109.

[13] Fujii, F. and Choong, K.K., "Branch-switching in Bifurcation of Structures", J. Struct. Eng., ASCE, 1992, Vol. 118, pp. 1578-1596.

[14] Fujii, F. and Asada, K. "Branch-switching in Simple Spatial Bifurcation Models", SEIKEN-1ASS Svmp. on Nonlinear Analysis and Design for Shells and Spatial Structures, 1993, Tokyo, pp. 515-522.

[15] Wriggers, P., Wagner, W. and Miehe, C., “A Quadratically Convergent Procedure for the Calculation of Stability Points in Finite Element Analysis”, Comput. Methods Appl. Mech. Engrg., 1988, Vol. 70, pp. 329-347.

[16] Wriggers., P., and Simo, J.C. "A General Procedure for the Direct Computation of Turning and Bifurcation Points”, Int. J. Numer. Meth. Engng, 1990, Vol. 30, pp. 155-176.

[17] Chan, S.L., "A Non-linear Numerical Method for Accurate Determination of Limit and Bifurcation Points”, Int. J. Numer. Meth. Engng., 1993, Vol. 36, pp. 2779-2790.

[18] Fujii, F. and Ramm, E. "Computational Bifurcation Theory-path-tracing, Pinpointing and Path-switching”, Engineering Structures, 1997, Vol. 19, pp. 385-392.

[19] Fujii, F., Ikeda, K., Noguchi, H. and Okazawa, S., "Modied Stiffness Iteration to Pinpoint Multiple Bifurcation Points”, Comput. Methods Appl. Mech. Engrg., 2001, Vol. 190 (18.19), pp. 2499-2522.

[20] Fujii, F. and Noguchi, H., "Eigenvector-free Indicator, Pinpointing and Brach-switching for Bifurcation”, Commun. Numer. Meth. Engng., 2003, Vol. 19, pp. 445-457. 
[21] Battini, J.M., Pacoste, C. and Eriksson, A., "Improved Minimal Augmentation Procedure for the Direct Computation of Critical Points”, Comput. Methods Appl. Mech. Engrg., 2003, Vol. 192, pp. 2169-2185.

[22] Oran, C., “Tangent Stiffness in Space Frame”, J. Struc. Div., ASCE, 1973, Vol. 99, No. 6, pp. 987-1001.

[23] Spillers, W.R., “Geometric Stiffness Matrix for Space Frames”, Computers \& Structures, 1990, Vol. 36, No. 1, pp. 29-37.

[24] Kassimali, A. and Abbasnia, R., "Large deformation analysis of elastic space frames”, J. Struct. Eng., ASCE, 1991, Vol. 117, No. 7, pp. 2067-2087.

[25] Abbasnia, R. and Kassimali, A., "Large Deformation Elastic-plastic Analysis of Space Frames”, J. Construct. Steel Research, 1995, Vol. 35, pp. 275-290.

[26] Levy, R. and Spillers, W.R., "Analysis of Geometrically Nonlinear Structures, 2nd ed.”, Kluwer Academic Publishers, 2003.

[27] Argyris, J., “An excursion into large rotations”, Comput. Methods Appl. Mech. Engrg., 1982, Vol. 32, pp. 85-155.

[28] Argyris, J.H., Dunne, P.C. and Scharpf, D.W., “On large displacement small strain analysis of structures with rotational degrees of freedom”, Comput. Methods Appl. Mech. Engrg., 1978, Vol. 14, pp. 401-451.

[29] Argyris, J.H., Balmer, H., Doltsinis, I.S.T., Dunne, P.C., Haase, M., Kleiber, M., Malejannakis G.A., Mlejnek, H.P., Muller, M. and Scharpf, D.W., "Finite element method-The natural approach”, Comput. Methods Appl. Mech. Engrg., 1979, Vol. 17/18, pp. $1-106$.

[30] Argyris, J.H., Hilpert, O., Malejannakis, G.A. and Scharpf, D.W., "On the geometrical stiffness of a beam in space-A consistent v.w. approach”, Comput. Methods Appl. Mech. Engrg., 1979, Vol. 20, pp. 105-131.

[31] Argyris, J.H., Boni, B., Hindenlang, U. and Kleiber, M., "Finite element analysis of two and three dimensional elasto-plasic frames-the natural approach", Comput. Methods Appl. Mech. Engrg., 1982, Vol. 35, pp. 221-248.

[32] Simo, J.C., "A finite strain beam formulation. Part I, The three-dimensional dynamic problem”, Comput. Methods Appl. Mech. Engrg., 1985, Vol. 49, pp. 55-70.

[33] Izzuddin, B.A. and Elnashai, A.S., "Eulerian formulation for large displacement analysis of space frames”, J. Eng. Mech., ASCE, 1993, Vol. 119, No. 3, pp. 549-569.

[34] Meek, J.L. and Tan, H.S., "Geometrically Nonlinear Analysis of Space Frames by an Incremental Iterative Technique”, Comput. Methods Appl. Mech. Engrg., 1984, Vol. 47, pp. 261-282.

[35] Chan, S.L., "Geometric and Material Nonlinear Analysis of Beam-Columns and Frames Using the Minimum Residual Displacement Method”, Int. J. Num. Meth. Eng., 1988, Vol. 26, No. 12, pp. 2657-2669.

[36] Crisfield, M.A. and Cole, G., "Co-rotational Beam Elements for Two and Three-dimensional Nonlinear Analysis, Discretisation Methods in Structural mechanics”, ed. G. Kuhn \& H. Mang, Spring-Verlag, 1989, pp. 115-124.

[37] Crisfield, M.A., “A Consistent Co-rotational Formulation for Nonlinear Three Dimensional Beam Elements”, Comput. Methods Appl. Mech. Engrg., 1990, Vol. 81, pp. 131-150.

[38] Nour-Omid, B. and Rankin, C.C., "Finite Rotation Analysis and Consistent Linearization using Projectors”, Comput. Methods Appl. Mech. Eng., 1991, Vol. 93, pp. 353-384.

[39] Teh, L.H. and Clarke, M.J., "Co-rotational and Lagrangian Formulations of Elastic Three-dimensional Beam Finite Elements”, J. Construct. Steel Research, 1998, Vol. 48, pp. 23-44.

[40] Battini, J.M. and Pacoste, C., "Co-rotational Beam Elements with Warping Effects in Instability Problems”, Comput. Methods Appl. Mech. Engrg., 2002, Vol. 191, pp. 1755-1789. 
[41] Chan, S.L. and Zhou, Z.H., "Pointwise Equilibrium Polynomial Element for Nonlinear Analysis of Frames”, J. Struct. Eng., ASCE, 1994, Vol. 120, pp. 1703-1717.

[42] Izzuddin, B.A., "Quartic Formulation for Elastic Beam-columns Subject to Thermal Effects”, J. Eng. Mech., ASCE, 1996, Vol. 122, pp. 861-71.

[43] Chan, S.L. and Zhou, Z.H., "Nonlinear Integrated Design and Analysis of Skeletal Structures by 1 Element Per Member”, Engineering Structures, 2000, Vol. 22, pp. 246-57.

[44] Liew, J.Y.R., Chen, H., Shanmugam, N.E. and Chen, W.F., "Improved Nonlinear Plastic Hinge Analysis of Space Frame Structures”, Engineering Structures, 2000, Vol. 22, pp. 1324-1338.

[45] Hangai, E. and Kawamata, S., "Perturbation Method in the Analysis of Geometrically Nonlinear and Stability Problems", Advances in Computational Methods in Structural Mechanics and Design, UAH Press, 1972, pp. 473-489.

[46] Sabir, A.B., and Lock, A.C., "Large Deflection, Geometrically Nonlinear Finite Element Analysis of Circular Arches”, Int. J. Mech. Sci. 1973, Vol. 15, pp. 37-47.

[47] Powell, G.H., “Theory of Nonlinear Elastic Structures”, J. Struct. Div. ASCE, 1969, Vol. 95, No. 12, pp.2687-2701.

[48] Chu, K.H., and Rampetsreiter, R.H., "Large Deflection Buckling of Space Frames”, J, Struct. Div., ASCE, Vol. 98, No. 12, pp. 2701-2722, 1972

[49] Papadrakakis, M. and Ghionis, P., "Conjugate Gradient Algorithms in Nonlinear Structural Analysis Problems”, Comput. Methods Appl. Mech. Engrg., 1986, Vol. 59, No. 1, pp. 11-27.

[50] Kondoh, K. and Atluri, S.N., "Simplified Finite Element Method for Large Deformation, Post-Buckling Analysis of Large Frame Structures, Using Explicurly Derived Tangent Stiffness Matrices”, Int. J. Num. Meth. Eng., 1986, Vol. 3, No. 1, pp. 69-90.

[51] Shi, G. and Atluri, S.N., "Elasto-plastic Large Deformation Analysis of Space-frames : A Plastic-hinge and Stress-based Explicit Derivation of Tangent Stiffness”, Int. J. Num. Meth. Eng., 1988, Vol. 26, pp. 589-615. 


\title{
STRENGTH AND DUCTILITY EVALUATION METHOD FOR STEEL BRIDGE PIER FRAMES CONSIDERING EFFECT OF SHEAR FAILURE
}

\author{
L. Kang ${ }^{1}$ and H.B. Ge ${ }^{2, *}$ \\ ${ }^{1}$ Post Doctoral Researcher, Dept. of Civil Engineering, Meijo University, Nagoya, 468-8502, Japan \\ E-mail: connielan@tom.com \\ ${ }^{2}$ Professor, Dept. of Civil Engineering, Meijo University, Nagoya, 468-8502, Japan. \\ *(Corresponding author: E-mail: gehanbin@meijo-u.ac.jp)
}

Received: 25 August 2011; Revised: 4 October 2011; Accepted: 21 November 2011

\begin{abstract}
This paper presents a practical evaluation method for predictions of strength and ductility capacity of steel bridge pier frames including effects of shear failure. The shearing behavior of structure is simulated by introducing membrane and truss elements at the mid-span of girder. In order to investigate the effects of shear failure on the strength and ductility capacity, a series of pushover analyses are carried out, comparisons between different methods are conducted and effects of sensitive parameters are discussed. From these investigations and discussions, the availability of the shear ductility prediction method proposed in this study is verified, especially for the unstiffened cases with large web width-thickness ratio of girder. Furthermore, a boundary between bending and shear failure modes is obtained based on discussions.
\end{abstract}

Keywords: Steel bridge pier frame, Shear failure, Bending failure, Ductility capacity, Membrane element, Web width-thickness ratio of beam

\section{INTRODUCTION}

Steel bridge piers suffered severe seismic damage during the Hyogoken-Nanbu earthquake, on January 17th, 1995. Some of steel bridge piers' failure during this earthquake mainly resulted from the shear local buckling, as shown in Figure 1. Severe shear damage in such structures caused considerable disruption to the relief work. This resulted in a consensus to be reached that the seismic capacity, especially the ductility, of such structures needs further and extensive investigation. Because no similar damage ever being reported in Japan before, shear failure, especially at the mid-span of girder, was not considered in seismic design prior to this earthquake. However, since then the necessity of accounting for the effect of shear failure in the phase of seismic design has been gradually realized. In the past years, the performance of bending failure has been deeply investigated [1-6]. For the shear failure of steel pier frames due to the shear local buckling, the experimental investigations have been conducted [7, 8], but the corresponding evaluation method is sparse and specific quantitative criterion to relate these failure modes to steel bridge piers is lacking. Besides, for steel bridge pier frames, both bending and shear failure verifications should be conducted in order to identify which type of failure will occur, especially during earthquake loading [9-11].

The shear failure of column-beam joint in building frames has been regarded as important damage mode [12, 13]. Because of the strengthening measures of pier-girder joint in steel bridge pier frames, large shear deformation may occur at the mid-span of girder [14]. Similar to the previous research [14-18], the strength and ductility should be considered and verified at the same time. A pushover analysis is terminated when any of the structure's failure criterion is satisfied and this state is taken as the ultimate state of the structure, based on which the ductility capacity of the structure can be determined. During the past years, there is a considerable amount of literatures on failure criterion. The bending failure criterion has been deeply studied in previous studies [1, 3-5, 19]. Besides, the shear failure criterion was studied [20, 21]. Although a simple analytical model 
considering shear deformation was discussed by Chusilp and Usami [21], the complete pushover analysis including shear failure for steel bridge pier frames has not been conducted because of the limitation of previous simulation model. The effect of shear failure on the ductility capacity of structure has not been studied in the previous research. In recent years, with the development of computational technology, the strength and ductility including effect of shear deformation and failure can be calculated and predicted accurately and easily. In the previous studies [20, 21], parameter analysis of shear deformation has been done and these results can provide basis for the proposed study. The aim of this study is to provide an analytical model to check and verify the strength and ductility including bending and shear failure modes for steel bridge pier frames more effectively.

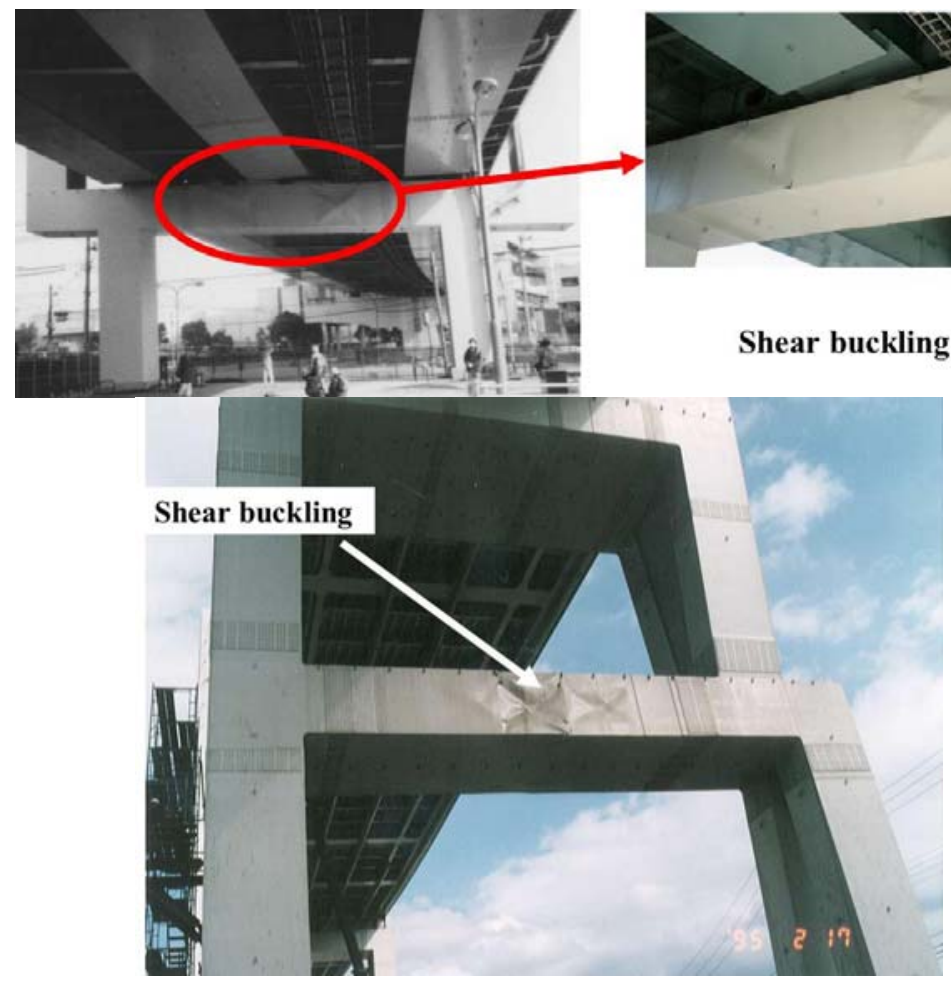

Figure 1. Examples of Shear Failure in Damaged Steel Bridge Pier Frames in the 1995 Kobe Earthquake

Because of the aforementioned lack of verification method about strength and ductility evaluation including shear failure in steel bridge pier frames, a hybrid model including beam, membrane and truss elements is proposed in this paper and a series of pushover analyses are carried out based on this model. First of all, a so-called MB model is established in section 2, in which the details including finite element model, dimensions, cross section, constraint between different elements and so on will be given. Secondly, the previous failure criteria are stated. Furthermore, comparisons between the proposed and previous models' results as well as sensitive parameter analysis are conducted. From the results and discussions, a boundary between bending and shear failure modes is obtained.

\section{FINITE ELEMENT ANALYTICAL MODEL OF STEEL BRIDGE PIER FRAMES}

In this study, the ABAQUS finite element software [22] was utilized to investigate the structural behavior of steel bridge pier frames. Two different finite element analytical models are established, which are BB and MB models, respectively, as shown in Figure 2. In which, the BB model only includes the beam element, and the MB model consists of the membrane and truss elements at the 
mid-span of girder except for the beam element. In the previous study [5], the BB model was employed to evaluate the bending performance of steel structures. In both two models, the P- $\triangle$ effect is taken into account, and the local buckling is ignored. For different models, the effect of shear behavior is taken into account in different ways. In the BB model, the shear deformation is included by using a type of beam element (i.e., B21) based on the Timoshenko beam theory, and the effect of shear failure is not considered. However, in the MB model, the shear deformation is also considered by introducing the membrane element at the mid-span of girder, which can take the effect of shear failure into account. The BB model only with the beam element can't take the effect of shear failure (as shown in Figure 1) into consideration, because the beam element can't accurately simulate the shear buckling occurring at the mid-span of girder. In this study, because the MB model with membrane element at the mid-span of girder can reveal the shear failure more comprehensively and correctly during pushover analysis, the MB model is employed to replace the traditional model (BB model), and the corresponding seismic verification method including the effect of shear failure by using this hybrid analytical model is developed and established.

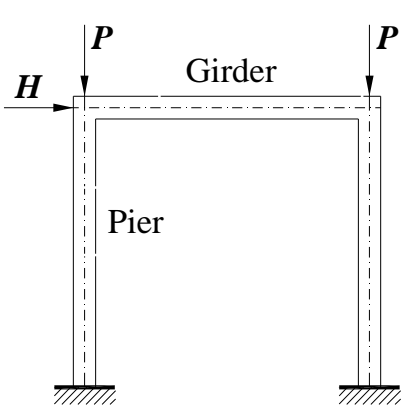

(a) Portal Frame of Steel Bridge Pier

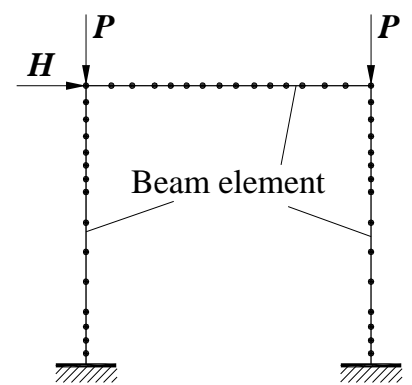

(b) BB Model

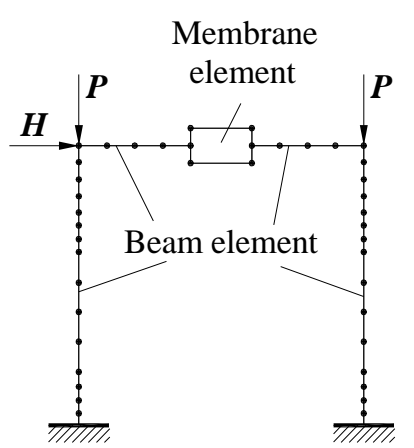

(c) MB Model

Figure 2. Steel Bridge Pier Frame

\subsection{Analytical Model}

\subsubsection{The analytical model only including beam element (BB model)}

The beam element (B21) in ABAQUS, which accounts for the shear deformation based on the Timoshenko beam theory, is utilized in this model, and each of girder and piers is divided into 15 beam elements [23]. Since this type of portal frame is commonly subjected to heavy loading, the plates at the pier-girder connections should be strengthened by doubling the plate thickness in order to avoid shear failure [14].

\subsubsection{The finite element model with membrane element at the mid-span of girder (MB model)}

In this analytical model, the beam element at the mid-span of girder is replaced by the membrane and truss elements. The four-node membrane element (M3D4) in ABAQUS, which has two degrees of freedom at each node, is adopted at the mid-span of girder, and in other parts of beam member the Timoshenko beam element is utilized (same to the BB model). Each pier member is divided into 15 beam elements [23]. The distance between the pier-girder joint and the membrane element is the length of 3 beam elements. Besides, same to the BB model, the plates at the pier-girder connections should be strengthened by doubling the plate thickness in order to avoid shear failure of joints [14]. The only difference between the BB model and MB model is the element type to model the mid-span girder. In order to predict the shear failure mode of steel bridge frame structure, the MB model consists of the membrane and truss elements except for the beam element, and it is then regarded as a hybrid model including three types of elements. 


\subsection{Dimensions of Analytical Model}

In this study, a series of finite element analyses are carried out. As shown in Figure 3, the label of analyzed models (e.g., US35-70A and SS35-40B) is defined as follows. The first letter indicates the type of cross section, where " $U$ " and "S" represent unstiffened box section and stiffened box section, respectively. The following letter S indicates steel bridge pier frame. Accordingly, "US" and "SS" refer to steel bridge pier frames with unstiffened steel box section and stiffened steel box section, respectively. The next two numbers denote the flange width-thickness ratio of column, $R_{f}$, and the web width-thickness ratio of beam, $R_{w b}$, respectively. They are 100 times larger than the actual value. The last letter (A or B) represents the beam length, where "A" means the length of beam is $8300 \mathrm{~mm}$, and " $\mathrm{B}$ " indicates the length is $12450 \mathrm{~mm}$. In other words, the values of $l / h$ in two cases are 0.769 and 1.15 , respectively. Additionally, for some unstiffened cases, in order to evaluate the effect of stiffened measure on the failure mode, stiffeners are employed and "-S" and "-2S" indicate one stiffener and two stiffeners to strengthen the unstiffened specimens, respectively. Some main parameters of finite element analysis are listed in Table 1. Equivalent web width-thickness ratios of beam $R_{w b}$ of $-\mathrm{S}$ and $-2 \mathrm{~S}$ cross sections are given in Table 2. A total of 38 different cases are analyzed in this study.

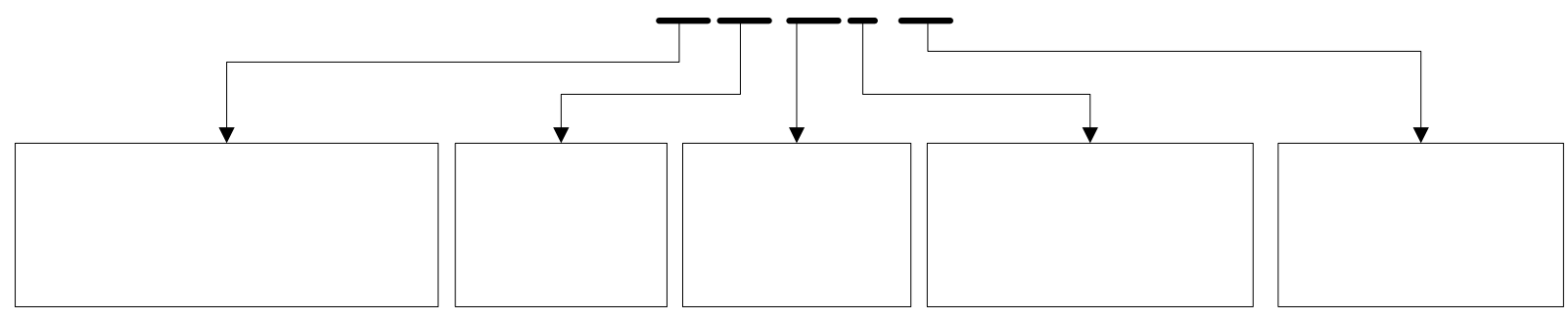

Figure 3. Label of Analytical Cases

Table 1. Main Parameters for Finite Element Analysis

\begin{tabular}{|l|l|}
\hline Parameters & Range \\
\hline Column height, $h(\mathrm{~mm})$ & 10800 \\
\hline Beam length, $l(\mathrm{~mm})$ & 8300,12450 \\
\hline $\begin{array}{l}\text { Flange width-thickness ratio of column, } \\
R_{f}\end{array}$ & $0.35 \sim 0.45$ \\
\hline Web width-thickness ratio of beam, $R_{w b}$ & $0.4 \sim 1.5$ \\
\hline Yield stress of steel (MPa) & 314 \\
\hline Stiffness ratio of column stiffener & 3.0 \\
\hline Stiffness ratio of beam stiffener & 1.0 \\
\hline
\end{tabular}

Table 2. Web Width-thickness Ratio of Beam $R_{w b}$ of -S and -2S Cross Sections

\begin{tabular}{|c|c|c|c|c|}
\hline Specimens & US35-60A-S & US35-70A-S & US35-100A-S & US35-150A-S \\
\hline$R_{w b}$ & 0.313 & 0.372 & 0.573 & 0.860 \\
\hline Specimens & US45-60A-S & US45-70A-S & US45-100A-S & US45-150A-S \\
\hline$R_{w b}$ & 0.308 & 0.363 & 0.540 & 0.811 \\
\hline Specimens & US35-100A-2S & US35-150A-2S & & \\
\hline$R_{w b}$ & 0.591 & 0.549 & & \\
\hline
\end{tabular}




\subsection{Cross Section of Steel Bridge Pier Frame}

For the BB model, the beam element at the mid-span of girder is shown in Figure 4(a). In which, $m, n$ are the two nodes of beam element, and the cross section of pier and girder members are introduced by sectional properties and parameters. For the beam cross sections, the web plate of beam is unstiffened belonging to US model and the web plate of beam is stiffened belonging to SS model. A box section with longitudinal stiffeners (SS model) is one of the most common cross-sectional types used for thin-walled steel structures. In the analysis of such structures, the original stiffened section can certainly be used but, for simplification, an equivalent unstiffened section is introduced [5].

However, in the MB model, the beam element at the mid-span of girder is replaced by membrane and truss elements, as shown in Figure 4(b). It is well-known that shear local buckling may occur at the mid-span of girder. In order to accurately predict the shear failure of steel bridge pier frames, one membrane and two truss elements are introduced into the MB model. The analytical method may be suitable for simulating the in-plane deformation of pushover analysis because the out-of-plane deformation can't be taken into account in membrane element. In addition, the two truss elements are used to model the flange plate at the mid-span of girder because the flange works mainly in tension or compression modes. In the Figure 4(b), $m, n$ are the two nodes of side beam elements, and $i, j, k, l$ are the four nodes of membrane element. Membrane and truss elements share the same nodes, in which $i$ and $j$ are two nodes of one truss element, $l$ and $k$ are two nodes of the other one. The thickness of membrane element is twice of the thickness of web plate based on equivalent cross section method. Cross section area of truss element is equal to that of flange plate of beam.

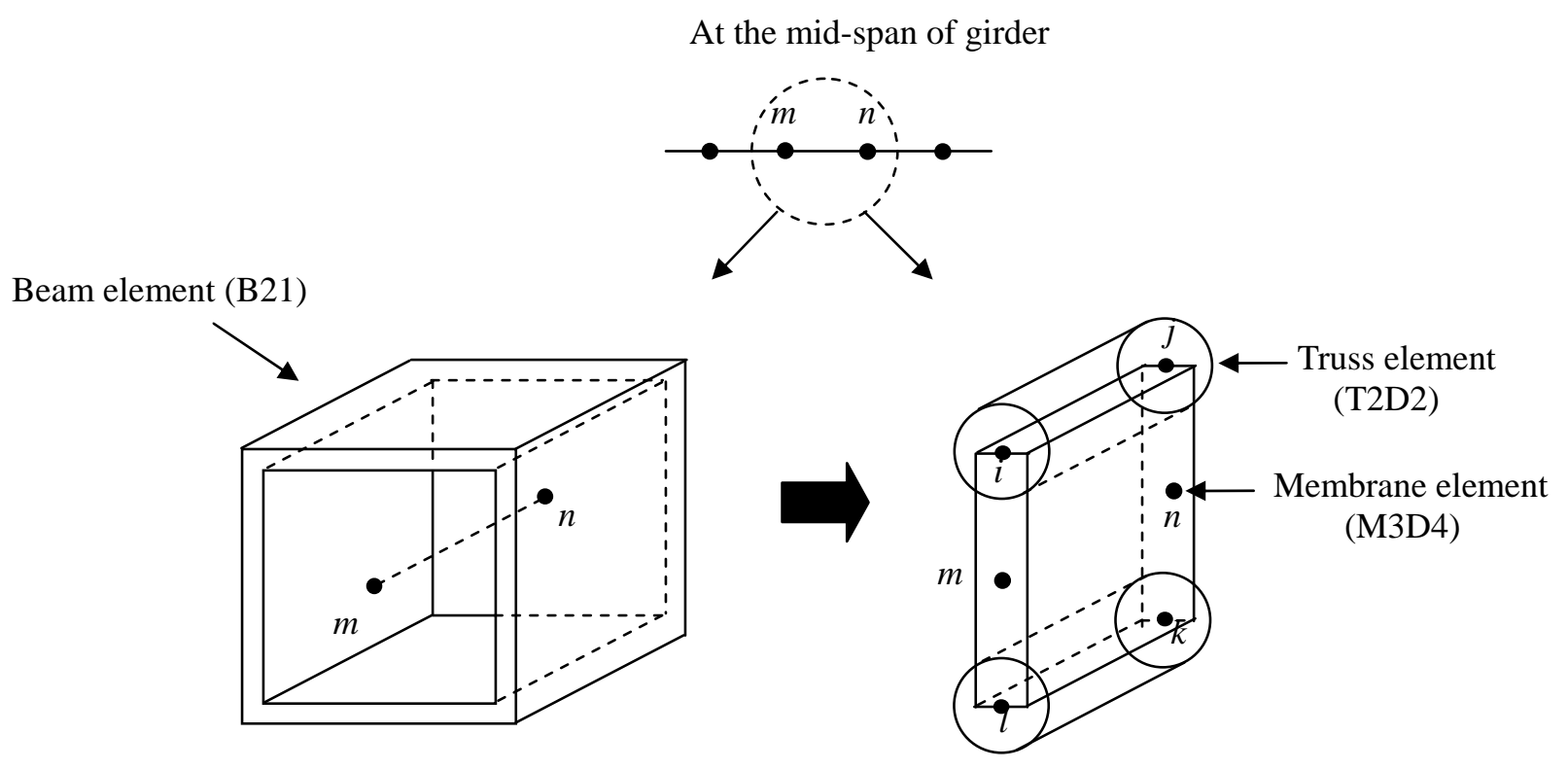

(a) Beam Element of BB Model

(b) Membrane and Truss Elements of MB Model

Figure 4. Difference between BB Model and MB Models 


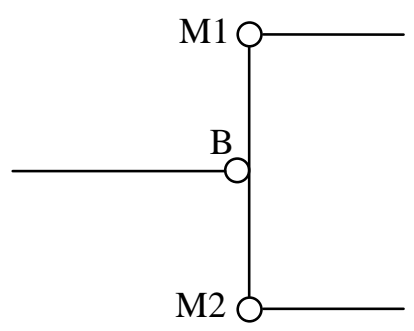

(a) Before Deformation

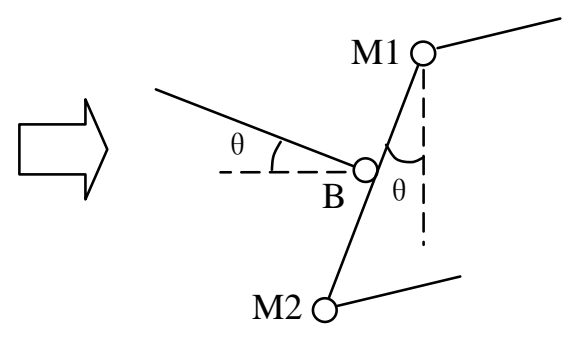

(b) After Deformation

Figure 5. Connection between Membrane and Beam Elements

\subsection{Constraint between Membrane and Beam Elements}

In the proposed analytical model, the connection between membrane and beam elements is established based on the assumption of plane cross section. In Figure 5, B is the node of beam element, and M1 and M2 represent the nodes of membrane element. There are two following constraint conditions:

(1) The length of the connection part (the length between nodes M1 and M2 in Figure 5), which connects membrane element with beam element, is constant;

(2) At the connection part between membrane and beam elements, the rotation of beam element node B is equal to the rotations of the two nodes (M1 and M2) of membrane element.

The displacement relationship between beam and membrane elements can be expressed as follows:

$u_{M}-u_{B}=\left(X_{A}-X_{B}\right)(\cos \theta-1)-\left(Y_{M}-Y_{B}\right) \sin \theta$

$v_{M}-v_{B}=\left(X_{M}-X_{B}\right) \sin \theta+\left(Y_{M}-Y_{B}\right)(\cos \theta-1)$

in which, $u$ and $v$ denote the displacements of $X$-axis and $Y$-axis, respectively. $X, Y$ represent the coordinate magnitudes of $X$-axis and $Y$-axis after deformation, respectively. The subscript $M$ expresses that the variable belongs to membrane element, and the subscript $B$ expresses that the variable belongs to beam element. $\theta$ denotes the rotation of beam element node.

\subsection{Weight of Upper Structure}

In this study, the weight of upper structure is regarded as vertical loads applying on the steel bridge pier frame. Based on the seismic coefficient method [24], the weight of upper structure is calculated. Considering a certain safety coefficient (in this study, is 1.14, same to the reference [23]), the analytical model is subjected to the horizontal load $H=0.2 P$ and the vertical loads of $P$ at the top of the steel bridge pier frame. The weight of upper structure is obtained. The range of $P / P_{y}$ is from 0.28 to 0.5 .

\section{FAILURE CRITERION}

The pushover analysis involves applying monotonic lateral loads to approximately simulate the horizontal displacements of steel bridge pier frames. In somewhat different formats, the pushover analysis has been proposed and evaluated mainly as a demand prediction tool for concrete structures [25-27]. In recent work of the authors [23, 28], the pushover analysis has been proposed for steel frame structures serving for both the capacity evaluation and demand prediction. During 
the pushover analysis, a proper failure criterion is necessary. For RC structures, the failure criterion is usually based on the rotational capacity of plastic hinges. However, the capacity of frame structures composed of thin-walled steel members is mainly controlled by local buckling. In this paper, a failure criterion including bending and shear failure modes is employed to evaluate bending and shear failure modes. Besides, the locations of failure verification, the damage degree and the effective failure length are described in the following sections.

\subsection{Location of Failure Verification}

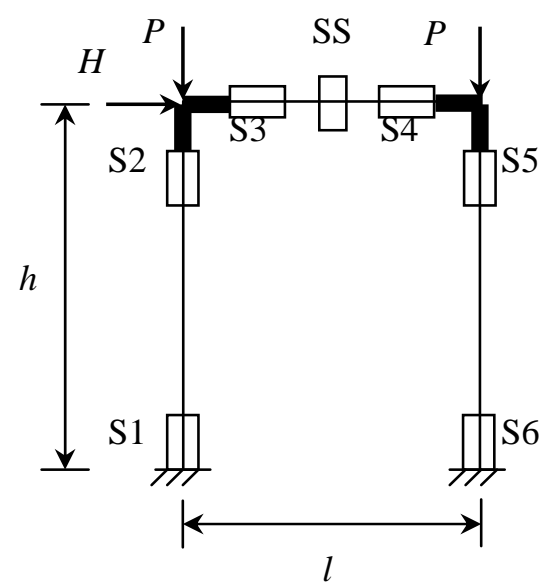

Figure 6. Location of Failure Verification

With the increase of loading, the failure verification locations become wider. Because the steel frame is under combined loading of bending and compression, the compression strain is raised [5]. To completely investigate the bending behavior of steel frames, six bending verification locations (S1 S6) are determined as shown in Figure 6, in which $l$ is the length of girder, $h$ is the height of pier, $P$ and $H$ are vertical and horizontal loads, respectively. Because the stiffness of the pier-girder joint is relatively large (as described in Sections 2.2 and 2.3), in this study, SS at the mid-span of girder is regarded as the shearing verification location, as shown in Figure 6.

\subsection{Failure Verification}

\subsubsection{Bending failure verification}

In the proposed ductility evaluation method, the bending failure criterion can be described by a damage index $D_{s b}$, which is defined:

$D_{s b}=\frac{\varepsilon_{a, s}}{\varepsilon_{u, s}}$

when $D_{s b}$ reaches 1.0 , the bending ultimate state of structure is considered to be attained. Here, $\varepsilon_{a, s}$ represents the average strain of the compressive flange (for the box section) over a certain effective failure length that will be discussed further below. The value $\varepsilon_{u, s}$ denotes the failure strain and, to define it, the empirical formulas obtained from stub-column analyses are employed.

The empirical formulas of the failure strains were proposed for thin-walled steel stub columns with box sections that are subjected to compression and bending. The behavior of box-sectioned stub-columns with and without longitudinal stiffeners has been extensively investigated under combined compression and bending, and corresponding empirical equations for the failure strains were given as follows [5]: 
For unstiffened box stub-columns:

$$
\frac{\varepsilon_{u, s}}{\varepsilon_{y}}=\frac{0.108\left(1-N / N_{y}\right)^{1.09}}{\left(R_{f}-0.2\right)^{3.26}}+3.58\left(1-N / N_{y}\right)^{0.839} \leq 20.0
$$

For stiffened box stub-columns:

$$
\frac{\varepsilon_{u, s}}{\varepsilon_{y}}=\frac{0.8\left(1-N / N_{y}\right)^{0.94}}{\left(R_{f} \cdot \bar{\lambda}_{s}^{0.18}-0.168\right)^{1.25}}+2.78\left(1-N / N_{y}\right)^{0.68} \leq 20.0
$$

in which, $P=$ axial force; $P_{y}=$ squash load; $R_{f}=$ flange width-thickness ratio parameter; and $\bar{\lambda}_{s}=$ stiffener's slenderness ratio parameter. The definitions of $R_{f}$ and $\bar{\lambda}_{s}$ can refer to the reference [19]. In this study, $R_{f}=0.3 \sim 0.7, N / N_{y}=0.0 \sim 0.5$. When the axial force is a tension, it will be taken to be zero.

\subsubsection{Shear failure verification}

In the proposed ductility procedure, the shear failure criterion can be described by a damage index $D_{s s}$, which is defined:

$$
D_{s s}=\frac{\gamma_{s}}{\gamma_{u, s}}
$$

in which, $\gamma_{s}$ is the shearing strain of membrane element, $\gamma_{u, s}$ is the ultimate strain obtained by the equations (7) and (8). Simple formulas are proposed for estimating the ductility capacity of box girders with and without longitudinal web stiffeners as follows [21, 29]:

For unstiffened cross section:

$$
\frac{\gamma_{u, s}}{\gamma_{y}}=\frac{0.142}{\left(R_{w b}-0.18\right)^{4.0}}+4.0 \leq 20.0
$$

For stiffened cross section:

$$
\frac{\gamma_{u, s}}{\gamma_{y}}=2.5+\frac{0.5}{R_{w b}^{6.0}} \leq 20.0
$$

$R_{w b}$ is the web width-thickness ratio of box girders. The limit scope of the equation (8) is $\gamma_{w s} \geq \gamma_{w s}{ }^{*}$, $1.0 \leq \alpha_{w b} \leq 2.0 . \alpha_{w b}$ is the web length-width ratio of the girder. The details can refer to the references [21, 29].

\subsection{Effective Failure Length}

The effective failure length $l_{e}$ of a box-sectioned member adopted in this method is assumed as $l_{e}=$ $\min \left\{0.7 B, l_{d}\right\}$ where $B$ is the flange width and $l_{d}$ is the distance between two adjacent diaphragms [5]. For pipe section stub-columns in compression and bending, an empirical equation for the critical length (i.e., the length giving the lowest strength) was proposed by Gao et al. [3], and this length is found to be about half of the mode length of collapse in local buckling (i.e., the so-called elephant foot bulge) observed in long columns with pipe sections under cyclic lateral loading [30]. 
On this basis, a modified equation (approximately doubling the critical length equation of short cylinders) is employed to define the effective failure length of thin-walled pipe section structures, which is given by Zheng et al. [5]:

$l_{e}=1.2\left(\frac{1}{R_{t}^{0.08}}-1\right) d$

The critical parts could be in more than one place in a framing structure, and all of them should be checked. In a thin-walled steel structure, the excessive deformation tends to intensify in a local part and consequently the redistribution of the stress becomes unexpected. Thus, once the failure criterion at any one of the critical parts is satisfied, the ultimate state of such a structure is thought to be reached.

\section{4. $\quad$ RESULTS AND DISCUSSIONS}

The purpose of this study is to propose an improved analytical model and to evaluate the bending and shear failure modes of steel bridge pier frames by using the proposed model. Therefore, a hybrid model including membrane and truss elements at the mid-span of girder is developed. In this section, first of all, by the comparison of the results between MB and BB models, the reliability of the proposed model is verified. Next, by analyzing the parameters' effect, the relationship between structural parameters and shear failure of steel bridge pier frames is investigated. Finally, by utilizing the proposed method, the cases with stiffened and unstiffened plates are analyzed, and the influences of stiffened measure on the ductility evaluation and failure mode are investigated.

\subsection{Comparison between MB and BB Models' Results}

Table 3. Comparison of Different Models’ Ductility Capacity

\begin{tabular}{|c|c|c|c|c|c|c|c|}
\hline Specimens & $\begin{array}{c}\text { BB } \\
\text { model } \\
\delta_{u b} / \delta_{y}\end{array}$ & $\begin{array}{c}\text { MB } \\
\text { model } \\
\delta_{u b} / \delta_{y}\end{array}$ & $\begin{array}{c}\text { MB } \\
\text { model } \\
\delta_{u s} / \delta_{y}\end{array}$ & Specimens & $\begin{array}{c}\text { BB } \\
\text { model } \\
\delta_{u b} / \delta_{y}\end{array}$ & $\begin{array}{c}\text { MB } \\
\text { model } \\
\delta_{u b} / \delta_{y}\end{array}$ & $\begin{array}{c}\text { MB } \\
\text { model } \\
\delta_{\text {us }} / \delta_{y}\end{array}$ \\
\hline US35-40A & 4.74 & 4.73 & 14.1 & SS35-40A & 3.28 & 3.96 & 8.67 \\
\hline US35-50A & 4.65 & 4.71 & 6.14 & SS35-50A & 3.37 & 3.82 & 9.50 \\
\hline US35-60A & 4.48 & 4.72 & 3.37 & SS35-60A & 3.22 & 3.52 & 7.13 \\
\hline US35-70A & 4.25 & 4.84 & 2.78 & SS35-70A & 3.22 & 3.28 & 4.85 \\
\hline US35-100A & 3.40 & 4.45 & 2.70 & SS45-40A & 2.48 & 2.53 & 6.07 \\
\hline US35-150A & 3.42 & 4.95 & 2.01 & SS45-50A & 2.34 & 2.36 & 5.98 \\
\hline US45-40A & 2.93 & 2.92 & 6.86 & SS45-60A & 2.34 & 2.34 & 4.85 \\
\hline US45-50A & 2.81 & 2.93 & 4.02 & SS45-70A & 2.34 & 2.34 & 3.59 \\
\hline US45-60A & 2.75 & 2.97 & 2.53 & SS35-40B & 3.99 & 3.96 & $\infty$ \\
\hline US45-70A & 2.63 & 2.90 & 2.03 & SS35-50B & 3.55 & 3.55 & 18.97 \\
\hline US45-100A & 2.50 & 2.89 & 1.90 & SS35-60B & 3.57 & 3.53 & 11.09 \\
\hline US45-150A & 2.47 & 3.03 & 1.41 & SS35-70B & 3.53 & 3.49 & 7.92 \\
\hline US35-60A-S & 4.53 & 4.50 & 27.9 & SS45-40B & 2.66 & 2.63 & 24.4 \\
\hline US35-70A-S & 4.21 & 4.20 & 19.1 & SS45-50B & 2.57 & 2.55 & 14.7 \\
\hline US35-100A-S & 3.42 & 3.94 & 7.65 & SS45-60B & 2.47 & 2.42 & 7.26 \\
\hline US35-150A-S & 3.49 & 4.56 & 2.43 & SS45-70B & 2.43 & 2.42 & 4.97 \\
\hline US45-60A-S & 2.74 & 2.74 & 12.9 & & & & \\
\hline US45-70A-S & 2.66 & 2.72 & 9.33 & & & & \\
\hline US45-100A-S & 2.47 & 2.61 & 5.72 & & & & \\
\hline US45-150A-S & 2.51 & 2.87 & 1.96 & & & & \\
\hline US35-150A-2S & 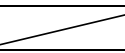 & 4.45 & 5.93 & & & & \\
\hline US45-150A-2S & 1 & 2.83 & 4.79 & & & & \\
\hline
\end{tabular}

Notes: Gray section means the minimum value between $\delta_{u b} / \delta_{y}$ and $\delta_{u s} / \delta_{y}$ of MB model. 
The computational results for the case of US35-70A by using MB and BB models are shown in Figure 7. Firstly, Figure 7(a) indicates the horizontal load versus horizontal displacement curves obtained from the MB and BB models. It demonstrates the relationship between $H / H_{y}$ ( $H$ is the horizontal load, $H_{y}$ is the horizontal yield load) and $\delta / \delta_{y}$ ( $\delta$ is the horizontal displacement, $\delta_{y}$ is the horizontal yield displacement) for the steel bridge pier frames. Secondly, Figure 7(b) illustrates the damage degree of steel frame versus horizontal displacement curves obtained from the finite element analysis of MB model. In Figure 7(b), the damage degrees of S2 S4 (S1 S6 are six locations of failure verification as shown in Figure 6) are relatively small, and then the magnitudes of S2 S4 are omitted in Figure 7(b). Lastly, Figure 7(c) demonstrates the damage degree versus horizontal displacement curves of the BB model. Table 3 reveals the ductility capacity of all the analytical examples obtained from finite element analyses of BB and MB models. $\delta_{u b} / \delta_{y}$ and $\delta$ us $/ \delta$ y represent the ratios of bending and shear ultimate-to-yield horizontal displacements, respectively. In this study, they are termed as the bending ductility and shear ductility, respectively.

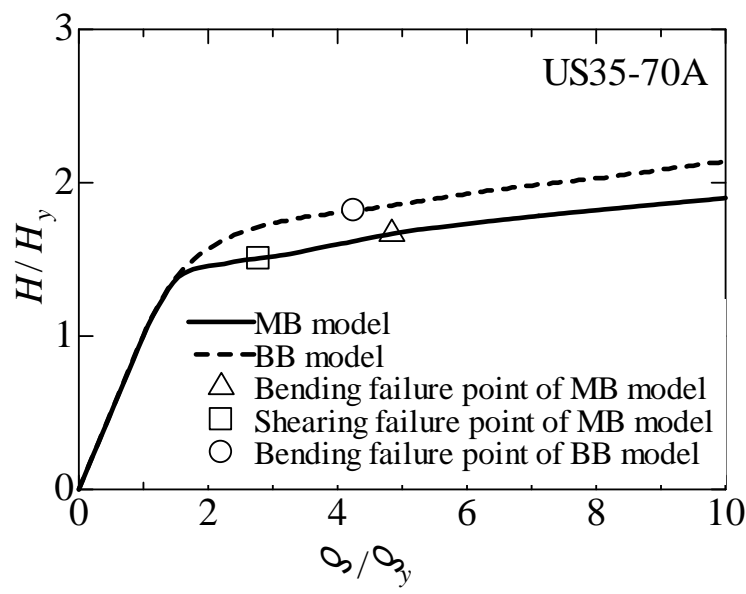

(a) Horizontal Load-displacement Curves and Failure Points of MB and BB Models

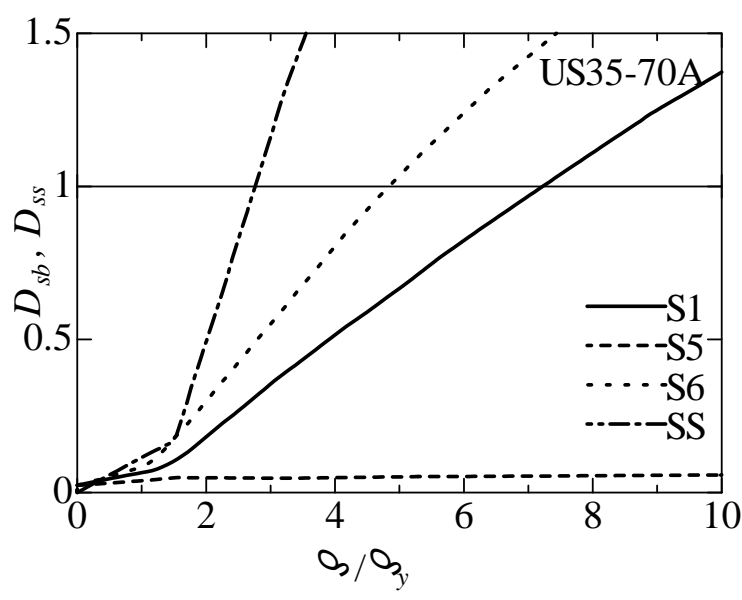

(b) Damage degree of MB Model 


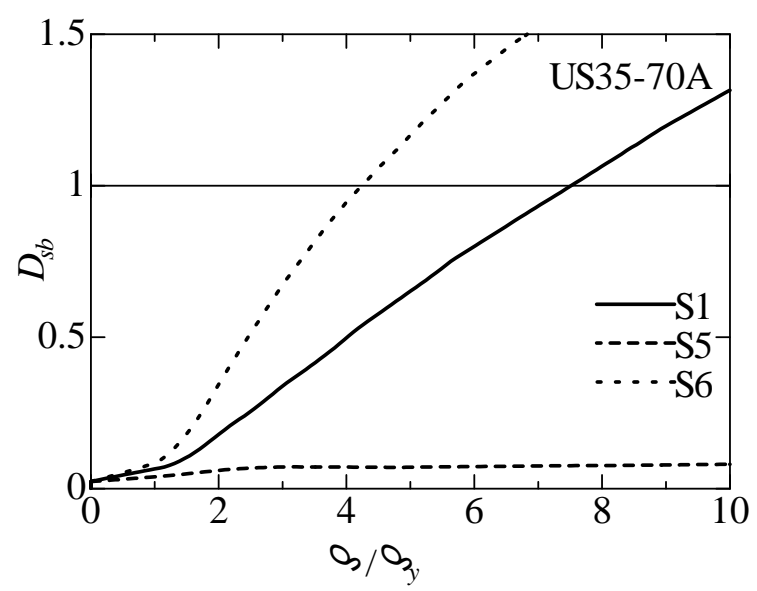

(c) Damage Degree of BB Model

Figure 7. Horizontal Load Displacement Curves and Damage Degree of MB and BB Models

Based on the analytical results of US35-70A as shown in Figure 7, the web width-thickness ratio of beam is comparatively large, and shear failure is predicted to occur at the mid-span of girder. Figure 7(a) reveals that the shear failure occurs before bending failure during the pushover analysis of MB model, and the steel frame may encounter shear failure firstly. Besides, the horizontal displacements of the MB model in this study are larger than that of BB model obtained from the previous method, which is used to evaluate the bending performance. From the analytical responses of Figure 7(b), we can observe that the shear damage degree of SS increases more quickly than the bending damage degree of other locations. Individual differences in simulation results may reflect differences in analytical models, specifically in the damage degree and horizontal displacement. In conclusion, the previous method, which only consists of beam element, can't be employed to predict the shear failure of steel bridge pier frames.

Furthermore, some differences may exist in the load-displacement curves between $\mathrm{MB}$ and $\mathrm{BB}$ models as shown in Figure 7. On one hand, when the magnitude of $\delta$ is near to $1.7 \delta_{y}$, the strength of BB model increases continuously and smoothly, however, for MB model the same phenomenon does not exist. It demonstrates that the web plate at mid-span of MB model's girder has reached the ultimate shear state. Because the shear failure mainly results in the horizontal displacement of steel frames, the strength increase will be delayed. On the other hand, the bending failure points obtained from $\mathrm{MB}$ and $\mathrm{BB}$ models are different. The large width-thickness ratio parameter leads to the decrease of shearing strength, and meanwhile the bending plastic damage may be delayed during the bending verification procedure because of the relatively large bending plastic deformation capacity. Consequently, for the cases of shearing beam with large width-thickness ratio parameter, the prediction precision of its failure mode will be improved by using the proposed method in this study.

\subsection{Effect of Web Width-thickness Ratio of Beam $\boldsymbol{R}_{w b}$}

Relationships between horizontal displacement and web width-thickness ratio of beam, $R_{w b}$, are illustrated in Figure 8. The shear ductility capacity of steel bridge pier frames is evaluated, and can be expressed as $\delta_{\text {us }} / \delta_{y}$. The results of unstiffened and stiffened models are shown in Figure 8, from which it is observed that the shear ductility decreases with the increase of $R_{w b}$. The similar conclusion is obtained from the previous research [20,21]. From the results of Figure 8, the shear ductility capacity of the examples with the flange width-thickness ratios of column $R_{f}=0.35$ is relatively larger compared with the examples with $R_{f}=0.45$. Based on the stiffness matching theory, for these analytical examples, the web width-thickness ratio of beam corresponding to large flange 
width-thickness ratio of column should be relatively large. Accordingly when the magnitude of model's $R_{f}$ is equal to 0.45 , its $R_{w b}$ should be relatively large. In other words, when the web plate of beam is thick, the shear ductility capacity of steel bridge pier frames might be large. The similar conclusion has been demonstrated in the previous study [20].

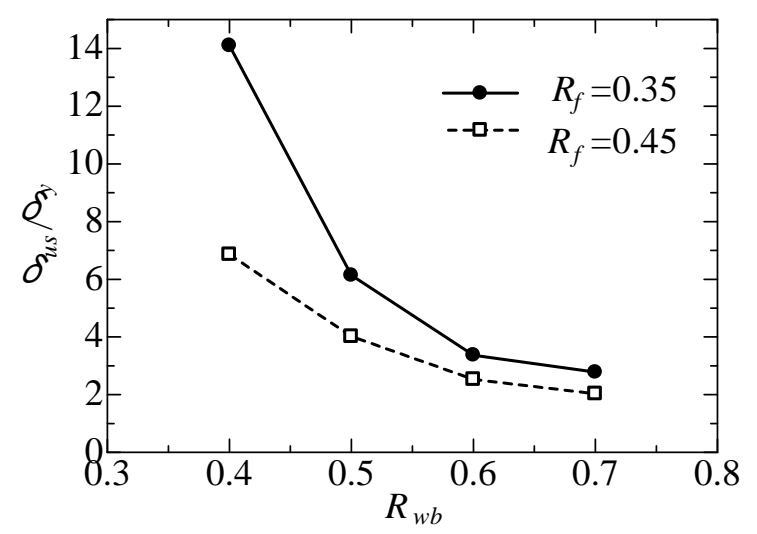

(a) Unstiffened Cross Section

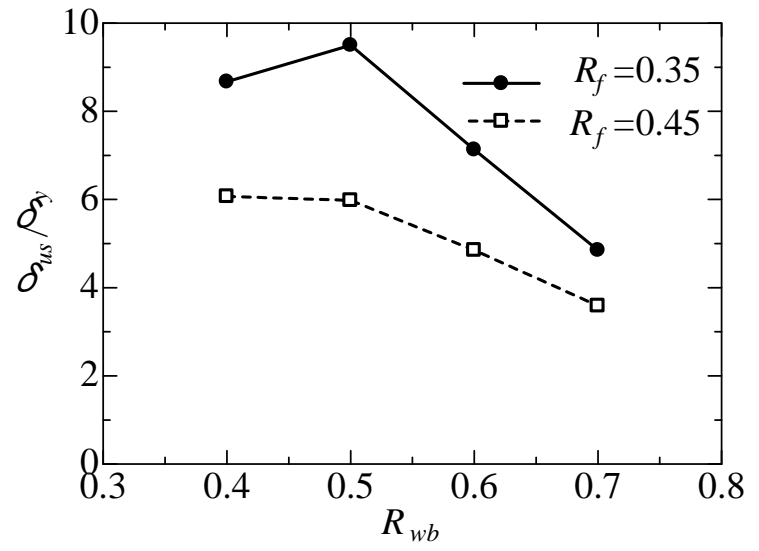

(b) Stiffened Cross Section $(l / h=0.769)$

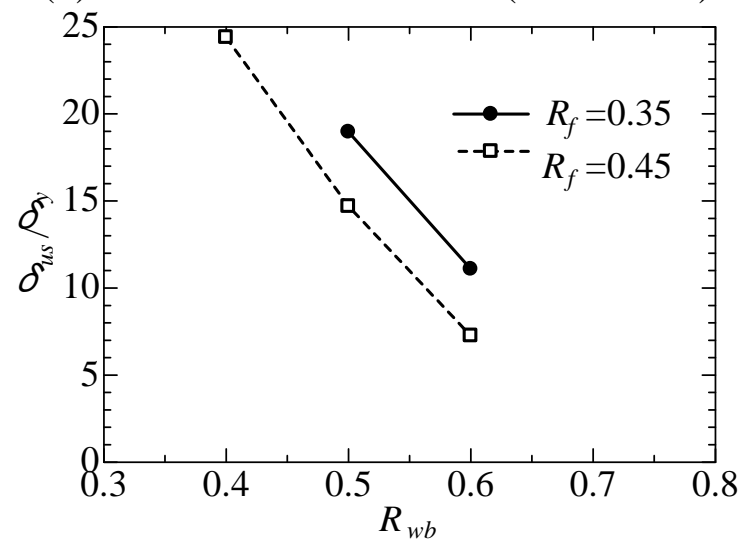

(c) Stiffened Cross Section $(l / h=1.15)$

Figure 8. Effect of Web Width-thickness Ratio of Beam, $R_{w b}$, on Shear Ductility Capacity of Steel Frames

\subsection{Comparison between Bending and Shear Failure Modes}

The horizontal displacements versus web width-thickness ratio of beam $R_{w b}$ curves are illustrated in Figure 9 obtained from the unstiffened cases. It is observed that the bending ductility of unstiffened structures decreases with the increase of $R_{w b}$, however, the shear ductility basically 
retains constant with the increase of $R_{w b}$. When $R_{w b}$ is larger than 0.6, although the ultimate bending displacement is near to the ultimate shear displacement, the first appearance of shear failure should not be ignored. In Figure 9, when $R_{w b}$ is equal to 0.4 and 0.5 , the bending failure occurs before the shear failure, but on the contrary when $R_{w b}$ is equal to $0.6 \sim 1.5$, the shear failure occurs before the bending failure. From the point of view of structural ductility, when $R_{w b}$ is equal to 0.4 and 0.5 , shear ductility is better than bending ductility, but when $R_{w b}$ is equal to $0.6 \sim 1.5$, the opposite is true. Figure 10 indicates the ultimate displacements $\delta_{u} / \delta_{y}$ of steel bridge pier frames, which combines the bending and shear cases. In Figure 11, all of computational results are given in the same figure. The solid and black mark means bending failure, and the hollow and white one means shear failure. For the cases with stiffened cross section, the bending failure is dominant. On the other hand, for the cases with unstiffened cross section, the shear failure plays a critical role when $R_{w b}$ is from 0.6 to 1.5. The above findings indicate that we can make a judgment between bending and shear failure modes by the magnitude of $R_{w b}$, and the approximate boundary of $R_{w b}$ is 0.6. Generally a pier frame may be designed to avoid the occurrence of shear failure. Therefore, its $R_{w b}$ should be less than 0.6. In this study, for some stiffened cases, the stiffener plates make the shear failure risk decrease, and for the unstiffened cases, maybe the shear failure occurs firstly when $R_{w b}$ is greater than 0.6. Consequently, the unstiffened cases should be verified and analyzed, and some stiffened measures for avoiding occurrence of shear failure should be taken into account. The discussions will be carried out deeply in following section 4.4.

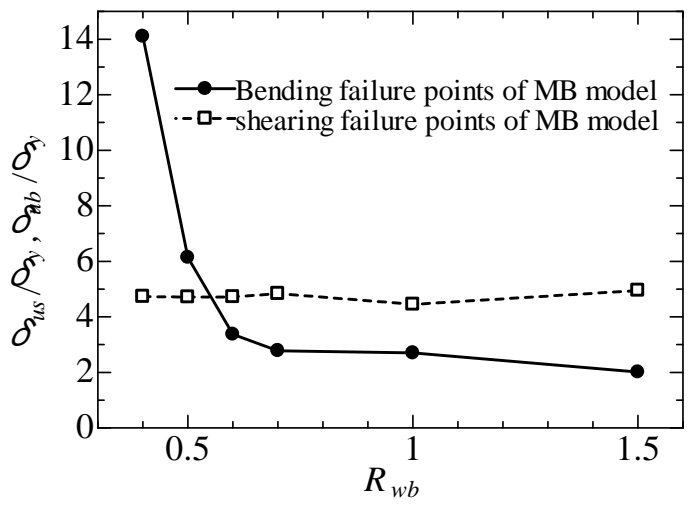

(a) US35-A Series

Figure 9. Comparison between Bending and Shear Failure Points

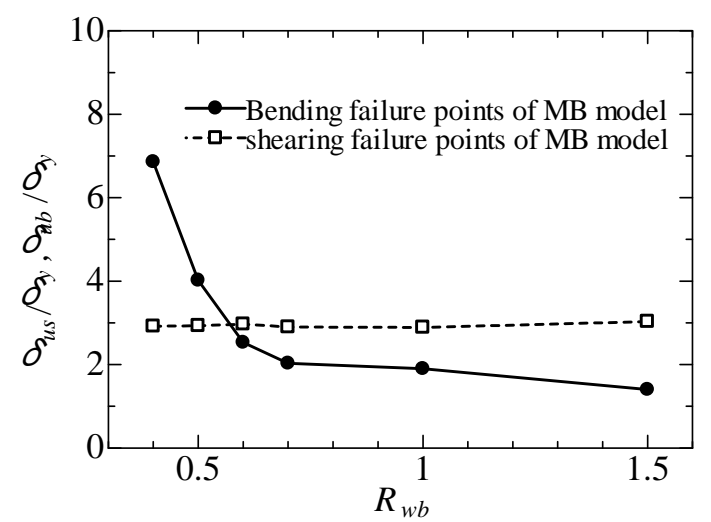

(b) US45-A Series (b) US45-A Series

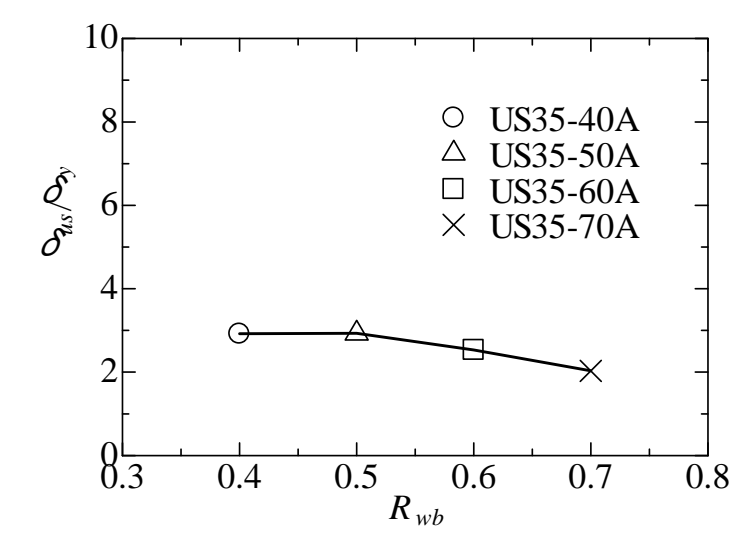

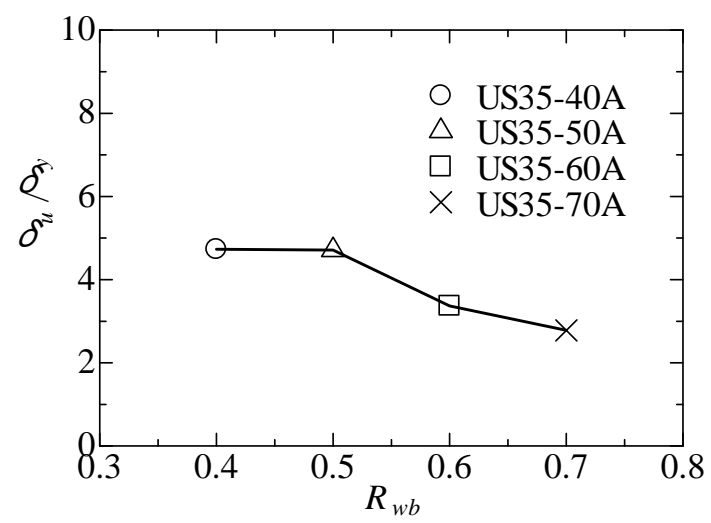

(a) US35-A Series
Figure 10. Ductility Capacity Combining Bending and Shearing Cases 


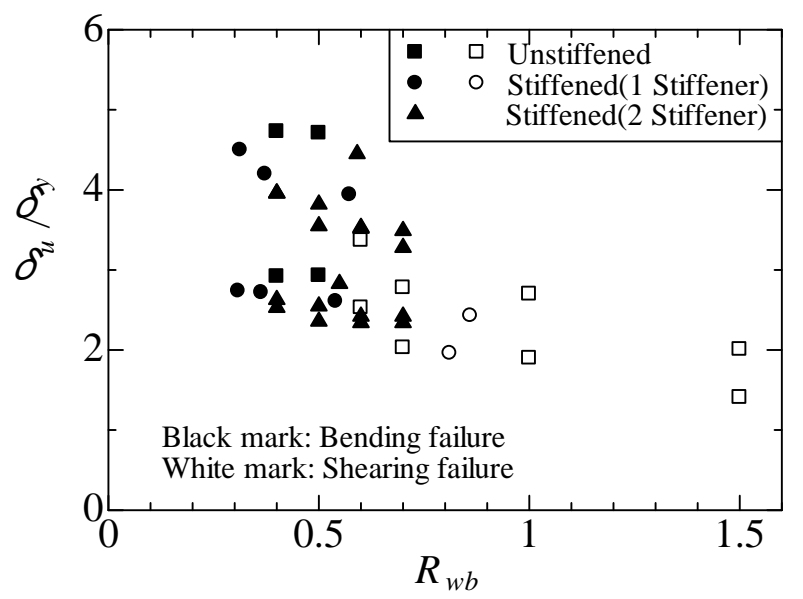

Figure 11. Relationship between Failure Modes (Bending and Shear Failure Modes) and Web Width-thickness Ratio of Beam $R_{w b}$

\subsection{Performance of Steel Frames with and without Stiffeners}

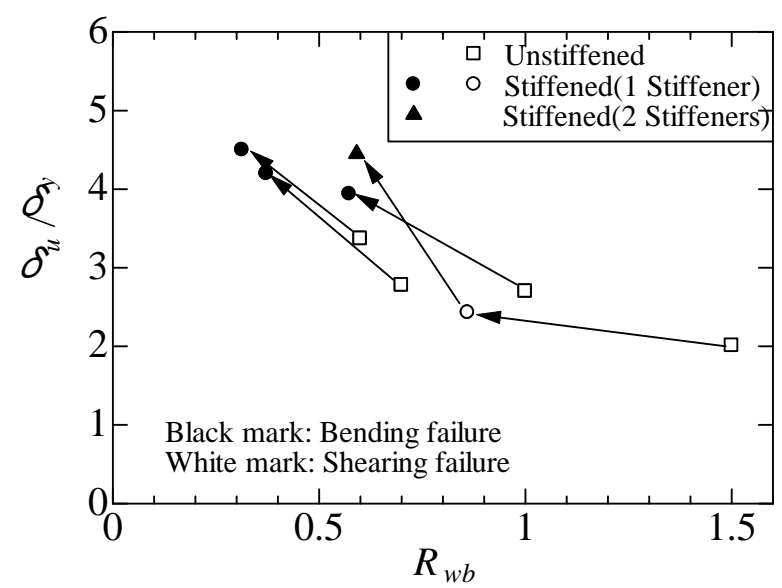

(a) $R_{f}=0.35$

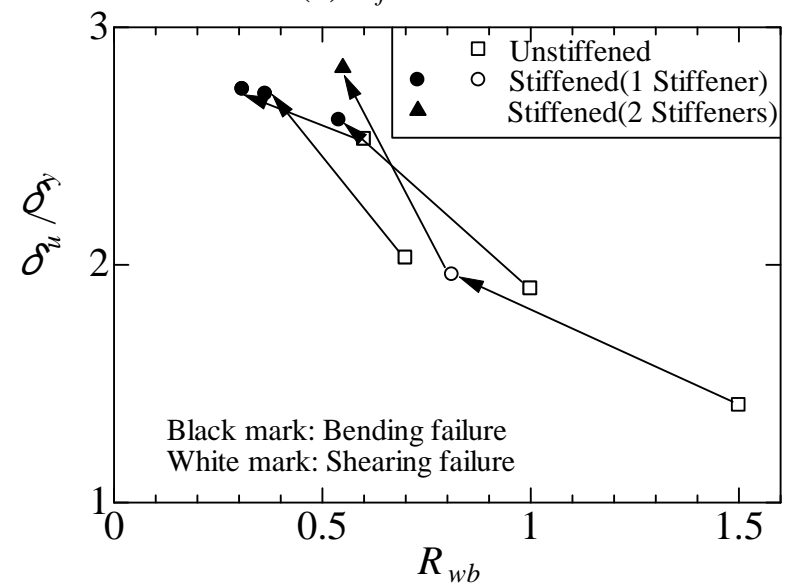

(b) $R_{f}=0.45$

Figure 12. Effect of Stiffener Plate on Failure Modes

Ductility evaluation of US35-60A 150A and US45-60A 150A conducted above reveals that their shear failure is dominant, and some stiffener measures should be taken to avoid shear failure. In order to investigate the effect of stiffener measures on the failure mode for steel frames, the analytical cases with and without stiffeners are conducted. The ultimate displacements $\delta_{u} / \delta_{y}$ versus web width-thickness ratio of beam $R_{w b}$ curves are shown in Figure 12. The figure 
illustrates how to improve ductility capacity, and how the failure mode translates from bending to shear failure by taking some stiffened measures. The flange width-thickness ratios $R_{f}$ of column and beam are 0.35 and 0.45 in Figure 11(a) and Figure 12(b) (ductility capacity), respectively. The following demonstrates and explains these figures.

(1) When the flange width-thickness ratio $R_{f}$ of column is 0.35 and 0.45 , the failure mode changes from shear to bending failure at $R_{w b}=0.6$, for $R_{w b}=1.0,0.7,0.6$, respectively. This discussion dose not include the case of $R_{w b}=1.5$, which has the thinnest web plate. Although for some stiffened cases in above analyses, shear failure will appear firstly when $R_{w b}>0.8, R_{w b}=0.6$ is regarded as the boundary from shear failure to bending failure, as described above.

(2) When the flange width-thickness ratio $R_{f}$ of column is 0.35 , its ductility capacity is more better than the case of $R_{f}=0.45$. The main reason of this result is that bending failure is dominant if the flange width-thickness ratio is relatively small.

Next, for the cases with the thinnest web plate, every web plate has two stiffeners. The web width-thickness ratio of beam $R_{w b}=0.591 \quad\left(R_{f}=0.35\right)$ and $R_{w b}=0.549 \quad\left(R_{f}=0.45\right)$, respectively. These computational results are given in Figure 12. The model with two stiffeners has undergone bending failure. The ductility capacity has been improved greatly.

Different marks refer to different stiffened sections as shown in Figures. 11 and 12. From these results, shear failure is prone to occur when $R_{w b}>0.6$. For this reason, in this study, the magnitude 0.6 of web width-thickness ratio of beam is regarded as the key parameter of identifying different failure types.

\section{SUMMARY AND CONCLUSIONS}

In this paper, a more accurate analytical method considering the effect of shear failure at the mid-span of girder was proposed to investigate the ductility performance of steel bridge pier frames. Different two simulation models, namely BB and MB models, were employed to evaluate the ductility and failure behavior of steel bridge pier frames. In the proposed MB model, membrane and truss elements were introduced. Moreover, comparisons between MB and BB models' results were carried out and parameter effect investigation was conducted. From the above discussions, we can draw the following conclusions:

(1) Comparison between the previous BB model's and the proposed MB model's results has been conducted in this study. The deformation of MB model is larger than that of BB model. The traditional method using the BB model cannot accurately take shear failure at mid-span of girder into account. However, in some cases the effect of shear failure on ductility capacity of steel frames should not be ignored, especially for the cases with large web width-thickness ratio of beam.

(2) Because shear failure is one of the main failure modes of the cases with unstiffened web plate of beam, the finite element analysis using the MB model is necessary. Compared with the $\mathrm{BB}$ model, the MB model can accurately predict the shear failure of steel bridge pier frames. When the bending failure is dominant, the proposed analysis method in this paper shows acceptable agreement with the previous method.

(3) The stiffener of beam web plate can greatly improve ductility capability of structures.

(4) The magnitude of beam web width-thickness ratio (0.6) is the key parameter of identifying different failure types (bending and shear failure modes). 
(5) The strength and ductility evaluation method of steel bridge pier frames can be effectively used to study the effects of various structural parameters which will be very useful in establishing design guidelines.

\section{ACKNOWLEDGMENT}

The first author is the post doctor researcher of Meijo University at Nagoya, Japan, who is supported by the Daiko Foundation. The author would like to thank to the Daiko Foundation for their financial assistance.

\section{REFERENCES}

[1] Nishikawa, K., Yamamoto, S., Natori, T., Terao, O., Yasunami, H., Terada, M., "An Experimental Study on Improvement of Seismic Performance of Existing Steel Bridge Piers", Journal of Structural Engineering, JSCE, 1996, Vol. 42, No. A, pp. 975-986 (in Japanese).

[2] White, D.W., Barth, K.E., "Strength and Ductility of Compact-flange I-girders in Negative Bending", Journal of Constructional Steel Research, 1998, Vol. 45, No. 3, pp. 241-280.

[3] Gao, S., Usami, T., Ge, H.B., "Ductility of Steel Short Cylinders in Compression and Bending", Journal of Engineering Mechanics, ASCE, 1998, Vol. 124, No. 2, pp. 176-183.

[4] Nishikawa, K., Murakoshi, J., Takahashi, M., Okamoto, T., Ikeda, S., Morishita, H., "Experimental Study on Strength and Ductility of Steel Portal Frame Pier", Journal of Structural Engineering, JSCE, 1999, Vol. 45, No. A, pp. 235-244 (in Japanese).

[5] Zheng, Y., Usami, T., Ge, H.B., "Ductility Evaluation Procedure for Thin-walled Steel Structures", Journal of Structural Engineering, ASCE, 2000, Vol. 126, No. 11, pp. 1312-1319.

[6] Susantha, K., Aoki, T., Kumano, T., Yamamoto, K., "Applicability of Low-yield-strength Steel for Ductility Improvement of Steel Bridge Piers", Engineering Structures, 2005, Vol. 27, No. 7, pp. 1064-1073.

[7] Hirano, T., Nishioka, T., Takada, Y., Yoshikawa, N., Matsuda, Y., "Report on Shear Strength of Web Panel in Cross Beam of Rigid Framed Steel Pier", Steel Construction Engineering, JSSC, 2006, Vol. 14, No. 11, pp. 527-534 (in Japanese).

[8] Miki, T., Yamada, O., Higuchi, N., "An Experimental Study on Elasto-plastic Behavior of Steel Web Plates under Cyclic Shearing Force", Journal of Structural Engineering, JSCE, 2007, Vol. 53, No. A, pp. 117-124 (in Japanese).

[9] Shen, Z., Zhang, Q., "Interaction of Local and Overall Instability of Compressed Box Columns", Journal of Structural Engineering, ASCE, 1991, Vol. 117, No. 11, pp. 3337-3355.

[10] Chan, S.L., Kitipornchai, S., Al-Bermani, F.G.A., "Elasto Plastic Analysis of Box Beam Columns Including Local Buckling Effects", Journal of Structural Engineering, ASCE, 1991, Vol. 117, No. 7, pp. 1946-1962.

[11] Fukumoto, Y., Uenoya, M., Nakamura, M., Kobayashi, Y., "Strength and Ductility of Plate Girder Panels under Cyclic Shear", Journal of Structural Engineering, JSCE, 2000, Vol. 46, No. 1, pp. 143-150 (in Japanese).

[12] Krawinkler, H., Popov, E.P., Bertero, V.V., "Shear Behavior of Steel Frame Joints", Journal of the Structural Division, ASCE, 1975, Vol. 101, No. 11, pp. 2317-2336.

[13] Ghobarah, A., Said, A., "Shear Strengthening of Beam-column Joints", Engineering Structures, 2002, Vol. 24, No. 7, pp. 881-888.

[14] Chen, Z.Y., Ge, H.B., Kasai, A., Usami, T., "Simplified Seismic Design Approach for Steel Portal Frame Piers with Hysteretic Dampers", Earthquake Engineering \& Structural Dynamics, 2007, Vol. 36, No. 4, pp. 541-562. 
[15] Nakamura, H., "Formulae for Evaluating Shear-bending Buckling Strength of Steel Piers with Circular Cross Section and Applicability of the Numerical Buckling Analysis Method", Proceedings of Nonlinear Numerical Analysis and Seismic Design of Steel Bridge Piers, Japan, 1997, Vol. 1, pp. 37-42 (in Japanese).

[16] Lee, S.C., "Strength of Plate Girder Web Panels under Pure Shear", Journal of Structural Engineering, ASCE, 1998, Vol. 124, No. 2, pp. 184-194.

[17] Morishita, N., Mori, H., Maeno, H., Okamoto, T., Nanoka, T., Usami, T., "Seismic Design of Steel Bridge Pier Frames Considering Shear Local Buckling in Beam Member", Proceedings of the 6th Symposium on Ductility Design Method for Bridges, Tokyo, 2003, Vol. 1, pp. 293-298 (in Japanese).

[18] Susantha, K.A.S., Aoki, T., Kumano, T., "Strength and Ductility Evaluation of Steel Bridge Piers with Linearly Tapered Plates", Journal of Constructional Steel Research, 2006, Vol. 62, No. 9, pp. 906-916.

[19] Zheng, Y., Usami, T., Ge, H.B., "Ductility of Thin-walled Steel Box Stub-columns", Journal of Structural Engineering, ASCE, 2000, Vol. 126, No. 11, pp. 1304-1311.

[20] Chusilp, P., Usami, T., "Strength and Ductility of Steel Box Girders under Cyclic Shear", Journal of Structural Engineering, ASCE, 2002, Vol. 128, No. 9, pp. 1130-1138.

[21] Chusilp, P., Usami, T., "New Elastic Stability Formulas for Multiple-stiffened Shear Panels", Journal of Structural Engineering, ASCE, 2002, Vol. 128, No. 6, pp. 833-836.

[22] ABAQUS, "ABAQUS/Analysis User's Manual-version 6.6", ABAQUS, Inc.: Pawtucket, RI, 2006.

[23] Usami, T., Zheng, Y., Ge, H.B., "Seismic Design Method for Thin-walled Steel Frame Structures", Journal of Structural Engineering, ASCE, 2001, Vol. 127, No. 2, pp. 137-144.

[24] JRA, "Specifications for Highway Bridges, Part V", Japanese Road Association, 1996 (in Japanese).

[25] Saiidi, M., Sozen, M.A., "Simple Nonlinear Seismic Analysis of R/C Structures", Journal of the Structural Division, ASCE, 1981, Vol. 107, No. 5, pp. 937-953.

[26] Collins, K.R., Wen, Y.K., Foutch, D.A., "Dual-level Sesmic Design: a Reliability-based Methodology", Earthquake Engineering \& Structural Dynamics, 1996, Vol. 25, No. 12, pp. 1433-1467.

[27] Bracci, J.M., Kunnath, S.K., Reinhorn, A.M., "Seismic Performance and Retrofit Evaluation of Reinforced Concrete Structures", Journal of Structural Engineering, ASCE, 1999, Vol. 123, No. 1, pp. 3-10.

[28] Zheng, Y., Usami, T., Ge, H.B., "Seismic Response Predictions of Multi-span Steel Bridges through Pshover Aalysis", Earthquake Engineering \& Structural Dynamics, 2003, Vol. 32, No. 8, pp. 1259-1274.

[29] Chusilp, P., Usami, T., Ge, H.B., Maeno, H., Aoki, T., "Cyclic Sear Bhaviour of Seel Bx Grders: Eperiment and Aalysis", Earthquake Engineering \& Structural Dynamics, 2002, Vol. 31, No. 11, pp. 1993-2014.

[30] Gao, S., Usami, T., Ge, H.B., "Ductility Ealuation of Seel Bidge Pers with Ppe Sctions", Journal of Engineering Mechanics, ASCE, 1998, Vol. 124, No. 3, pp. 260-267. 